Article

\title{
Omega-3 Fatty Acids and Eye Health: Opinions and Self-Reported Practice Behaviors of Optometrists in Australia and New Zealand
}

\author{
Alexis Ceecee Zhang ${ }^{1}\left(\mathbb{D}\right.$, Sumeer Singh ${ }^{1}\left(\mathbb{D}\right.$, Jennifer P. Craig ${ }^{2}$ and Laura E. Downie ${ }^{1, *(\mathbb{C}}$ \\ 1 Department of Optometry and Vision Sciences, The University of Melbourne, Carlton, VIC 3053, Australia; \\ alexisz@student.unimelb.edu.au (A.C.Z.); shari@student.unimelb.edu.au (S.S.) \\ 2 Department of Ophthalmology, New Zealand National Eye Centre, The University of Auckland, \\ Auckland 1023, New Zealand; jp.craig@auckland.ac.nz \\ * Correspondence: ldownie@unimelb.edu.au; Tel.: +61-3-9035-3043; Fax: +61-3-9035-9905
}

Received: 14 March 2020; Accepted: 16 April 2020; Published: 22 April 2020

\begin{abstract}
This study investigated optometrists' attitudes and self-reported practice behaviors towards omega-3 fatty acids for eye health, and knowledge and understanding of their potential risks and benefits. An anonymous online survey was distributed to optometrists in Australia and New Zealand. Questions included practitioner demographics and practice modality; self-reported practices and recommendations relating to diet, nutritional supplements, and omega-3 fatty acids for age-related macular degeneration (AMD) and dry eye disease (DED); and practitioner knowledge about omega-3 fatty acids. Of 206 included surveys, most respondents (79\%) indicated recommending for their patients to consume omega-3 fatty acids to improve their eye health. Sixty-eight percent of respondents indicated recommending omega-3-rich foods for AMD management, while 62\% indicated recommending omega-3 supplements. Most respondents (78\%) indicated recommending omega-3-rich foods or supplements for DED. For DED, recommended omega-3 supplement dosages were (median [inter-quartile range, IQR]) $2000 \mathrm{mg}$ [1000-2750 mg] per day. The main sources of information reported by respondents to guide their clinical decision making were continuing education articles and conferences. In conclusion, optometrists routinely make clinical recommendations about diet and omega-3 fatty acids. Future education could target improving optometrists' knowledge of differences in the evidence for whole-food versus supplement sources of omega-3 fatty acids in AMD. Further research is needed to address uncertainties in the evidence regarding optimal omega- 3 dosage and formulation composition in DED.
\end{abstract}

Keywords: omega-3; fatty acid; diet; supplement; optometrist; survey; nutrition; practice; eye disease; dry eye; age-related macular degeneration

\section{Introduction}

Diet is a major lifestyle factor that can influence eye health [1]. There is evidence to suggest that diets rich in omega-3 essential fatty acids, obtained from food sources or supplementation, may have ocular benefits. Omega-3 fatty acids are termed 'essential' as they cannot be synthesized in the body and, thus, must be obtained from the diet. The other major essential fatty acid family is the omega- 6 fatty acids. A person's dietary intake and balance of omega- 6 and omega- 3 fatty acids has been reported to be important for regulating vascular activity, mediating immune and nervous system function, and influencing the balance of systemic lipid-derived mediators [2].

Omega-3 fatty acids can be obtained from several sources. Short-chain omega-3, alpha-linoleic acid (ALA), is found mostly in plant-based foods (e.g., flaxseed, chia seeds). Long-chain omega-3 fatty acids, docosahexaenoic acid (DHA) and eicosapentaenoic acid (EPA), are predominantly obtained from 
marine-based foods (e.g., oily fish). As the biological conversion of ALA to EPA and DHA is incomplete in vivo (estimated in the range of 5 to $20 \%$ conversion) [3-5], direct intake of long-chain omega- 3 fatty acids is considered preferable [6]. Once ingested, long-chain omega-3 fatty acids compete with the long-chain omega-6 fatty acid, arachidonic acid (AA), for incorporation into cellular membranes [7]. Countering pro-inflammatory AA-mediated pathways, increasing omega-3 fatty acid intake modulates systemic inflammation through the production of anti-inflammatory metabolites. The optimal ratio of dietary omega- 6 to omega-3 is considered to be approximately 4 to 1 [8]. Excessive consumption of foods rich in omega- 6 fatty acids, a recognized feature of modern Western diets, can shift the omega-6:omega-3 ratio closer to 15 to 1 [8]. Moreover, it has been reported that up to $80 \%$ of adults in developed countries may not obtain the daily, recommended dietary intake of long-chain omega-3 fatty acids for optimal health [9]. Diets rich in long-chain omega-3 fatty acids have been suggested to provide long-term benefits for several chronic ocular conditions, including dry eye disease (DED) and age-related macular degenerations (AMD) [10,11].

DED is one of the most common reasons for patients to seek ophthalmic care [12]. DED can impose a significant burden on quality of life and is associated with substantial direct and indirect health costs $[13,14]$. The condition is characterized by a loss of tear film homeostasis and potential disruption to ocular surface integrity [15]. DED is commonly associated with ocular surface inflammation [16]. Dietary modification with omega-3 fatty acids is thought to reduce DED symptoms and signs by modulating ocular surface inflammation and improving tear-lipid profiles $[17,18]$. The United States (US) Women's Health Study showed a higher incidence of DED in women with low dietary omega-3 fatty acid intake [19]. However, clinical trials assessing the potential effects of omega-3 supplementation on the clinical expression of DED have presented apparently contradictory findings [20-24]. A recent Cochrane systematic review concluded that while a possible role exists for long-chain omega-3 supplements in managing DED, the best available evidence is currently uncertain and inconsistent [25]. The role of omega- 3 fatty acids in the management of DED is, thus, of continued interest and debate.

In addition to its anti-inflammatory effects, DHA is implicated in maintaining the structural and functional properties of the retina [26]. Diets rich in polyunsaturated fatty acids improve the retinal cellular response to ischemic, oxidative, and inflammatory damage in animal models of AMD [27-29]. Epidemiology studies have associated dietary long-chain omega-3 intake with a lower risk of developing early-stage AMD [30] and progression to late-stage, sight-threatening forms of disease [31]. However, omega-3 nutritional supplements have been shown not to confer the same benefit of reducing the risk of developing AMD as whole foods [32]. The reason for this difference in efficacy may be potential synergistic interactions of fatty acids with other nutrients and vitamins that are present in whole foods but not supplements [33]; these differences should be recognized when clinical recommendations relating to omega-3 fatty acids are made for AMD.

Eye care clinicians have an important role in informing their patients and the public about modifiable risk factors for ocular disease, including diet. Optometrists, as major providers of primary eye care in Australia and New Zealand, are ideally positioned to counsel patients about the benefits and risks of nutritional supplements and their potential impact on eye health. Two studies have investigated the self-reported recommendations made by optometrists relating to nutrition. In the UK, Lawrenson and Evans (2013) reported active engagement by optometrists in providing nutritional advice relating to AMD, but highlighted a need for increased awareness of the relevant research evidence [34]. In an Australian study of self-reported optometric practice patterns, Downie and Keller (2015) found $60 \%$ of optometrists indicated routinely asking their patients about diet, and approximately half indicated asking about nutritional supplement intake [35]. To date, no studies have specifically investigated eye care practitioner recommendations relating to omega-3 fatty acids.

In both Australia and New Zealand, the professional scope of optometry includes the diagnosis, assessment, and management of ocular disorders, including the prescription of topical and, in New Zealand, oral medications. In both countries, optometrists are assessed to equivalent competency standards [36]. Research has highlighted that most of the general public who seek optometric care 
expect to be counselled about their diet, as it relates to their eye health [37]. It is, thus, critical that the information delivered by eye care providers is accurate and up to date.

The aim of this study was to investigate the current attitudes and self-reported practice behaviors of optometrists towards omega-3 fatty acid recommendations for eye health, and to assess their opinions and understanding of the potential benefits and risks associated with oral omega- 3 fatty acid intake.

\section{Materials and Methods}

\subsection{Participants}

An anonymous, web-based survey was distributed to optometrists in Australia and New Zealand from June to October 2019. The survey was circulated electronically through professional organizations (Optometry Australia and associated early career networks, Cornea and Contact Lens Society of Australia, New Zealand Association of Optometrists, and Cornea and Contact Lens Society, New Zealand) and at a major national professional education conference, held in Melbourne Australia (July 2019).

The project was approved by both the University of Melbourne Human Research Ethics Committee (HREC \#1853287.1) and University of Auckland Human Participants Ethics Committee on 12 March 2019 for three years (ref. 022730).

\subsection{Survey Design}

This survey was administered using Qualtrics (Qualtrics, Provo, UT, USA) and comprised 39 questions, divided into four sections. Questions within each section sought responses that included: Select yes/no, select all that apply, select one option only, and optional free-text boxes. Reviewing or altering prior responses was not permitted. The survey was piloted to optimize the clarity of questions and the flow. Respondents were informed at the beginning of Section 2 that, for the purpose of this survey, diet was defined as "the food(s) and drink(s) that are regularly consumed".

Figure 1 illustrates the survey flow and question logic. As summarized in Table 1, the survey's four sections comprised: (1) Participant demographics, (2) self-reported clinical practices relating to diet and nutritional supplementation, (3a) clinical approach to recommending omega-3 fatty acids for AMD and DED, or ( $3 b$ ) reason(s) for not making omega-3 recommendations or for recommending that patients not consume omega-3 fatty acids, (4) knowledge relating to omega-3 fatty acids.

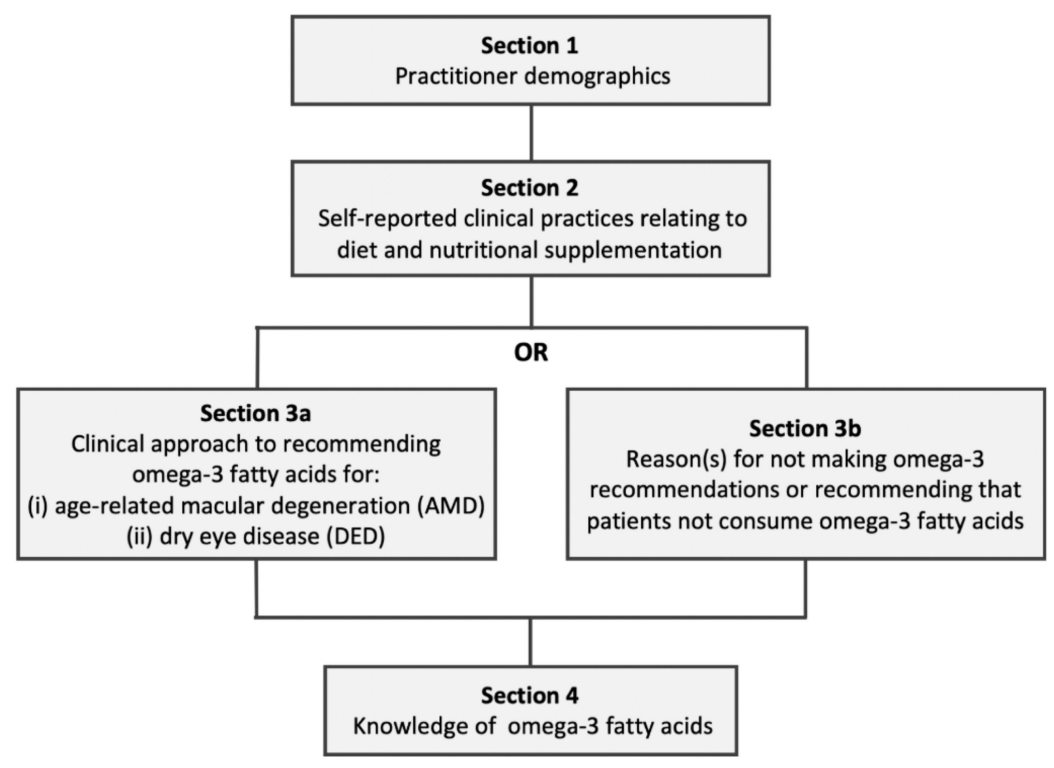

Figure 1. Survey structure. 
After completing Section 2, branch logic was used to direct respondents to either Section 3a or Section $3 \mathrm{~b}$ depending on their current general clinical approach to omega-3 fatty acids, according to their response to the following three options:

(1) I make recommendations for my patients to consume omega-3 fatty acids (in either oral supplementation form or via dietary modification) to improve their ocular health;

(2) I do not make recommendations for my patients to consume omega-3 fatty acids (in either oral supplementation form or via dietary modification) to improve their ocular health;

(3) I recommend for my patients not to consume omega-3 fatty acids to improve their ocular health.

Participants who selected option (1) were directed to complete Section 3a (to obtain data about their clinical recommendations relating to omega-3 fatty acids for AMD and DED). Participants who selected options (2) or (3) were directed to complete Section $3 b$ (to explore reasons for not making clinical recommendations relating to omega-3, or recommending that patients not consume omega-3 fatty acids).

Table 1. Summary of survey questions.

\begin{tabular}{|c|c|}
\hline Section & Question Surveyed \\
\hline $\begin{array}{l}\text { 1. Practitioner } \\
\text { demographics }\end{array}$ & $\begin{array}{ll}\text { - } & \text { Gender } \\
\text { - } & \text { Age } \\
\text { - } & \text { Location of optometry degree completion } \\
\text { - } & \text { Year of graduation from optometry degree } \\
\text { - } & \text { Postcode of principal practice } \\
\text { - } & \text { Therapeutic endorsement status } \\
\text { - } & \text { Mode of optometry practice (academic, corporate, hospital clinic or public health } \\
\text { - } & \text { clinic, independent, refractive surgery clinic, other) } \\
\text { - } & \text { Apprage hours per week providing patient care } \\
\text { - } & \text { Areas of self years, } 41-60 \text { years, over } 60 \text { years, so that percentages summed to } 100 \% \text { ) } \\
\text { surface disease, gerontology or aged care, glaucoma, myopia, paediatrics or } \\
\text { binocular vision, retinal disease, other) }\end{array}$ \\
\hline $\begin{array}{l}\text { 2. Self-reported } \\
\text { clinical practices } \\
\text { relating to diet and } \\
\text { nutritional } \\
\text { supplementation }\end{array}$ & $\begin{array}{l}\text { - Frequency of enquiry about patients' diet (never, rarely, sometimes, often } \\
\text { or always) } \\
\text { - Whether quantitative tools were used to survey dietary habits * } \\
\text { - } \quad \text { Frequency of enquiry about patients' usual intake of nutritional/vitamin } \\
\text { - } \quad \text { Frequency of providing dietary advice to patients (never, rarely, sometimes, often } \\
\text { or always) } \\
\text { - Statement that best describes respondents' current general clinical approach to } \\
\text { omega-3 fatty acid recommendations for ocular health } \\
\text { - Sources of information used to guide clinical decision-making regarding omega-3 } \\
\text { - } \quad \text { Patty acids } \\
\text { - Percentage of patients seen in practice estimated to have AMD }\end{array}$ \\
\hline
\end{tabular}


Table 1. Cont.

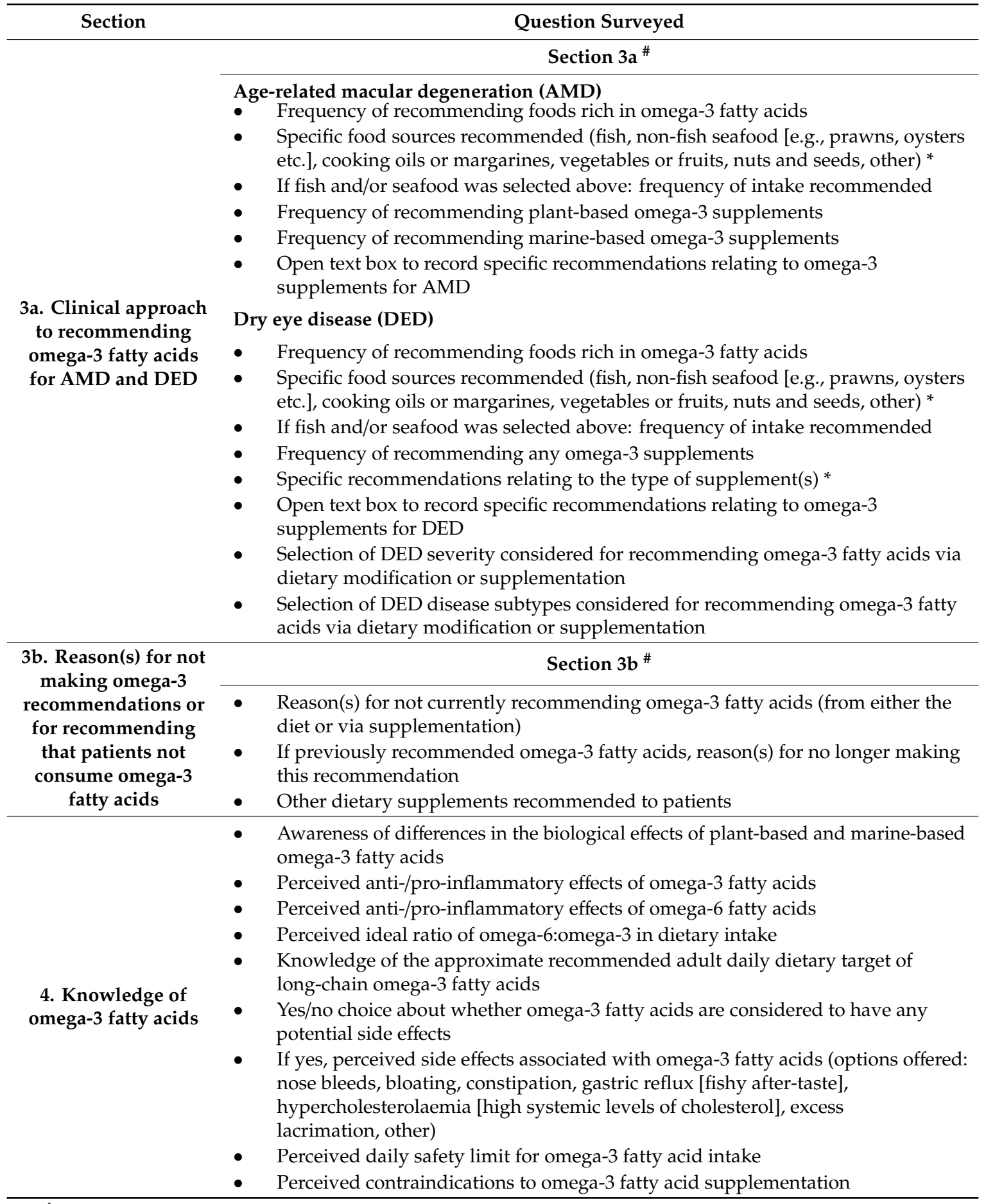

Stratification question, depending on the response selected, participants were directed to either Section 3a or Section 3b. \# Only one of these sections was displayed to the respondent. * Only displayed if any answers other than "Never" were selected in the previous question. AMD, age-related macular degeneration; DED, dry eye disease.

\subsection{Data Analysis}

Data contributed by optometrists practicing outside of Australia or New Zealand, or from participants who did not complete the survey up to the end of Section 3, were not included in the analysis. 
Statistical analysis was performed using IBM SPSS statistics software version 21.0 (https://www. ibm.com/analytics/spss-statistics-software). Graphs were plotted in GraphPad PRISM (version 6.01 for Windows, GraphPad Software, La Jolla, CA, USA, www.graphpad.com). Descriptive statistics were used to analyze participant demographics, clinical practices relating to diet and nutrition, clinical practice relating to omega-3 fatty acids, and practitioner knowledge of omega- 3 fatty acids. Fisher's exact test was used to compare data relating to the proportions of respondents across different groups. Specific recommendations relating to omega-3 supplementation, derived from responses in the free-text boxes, were represented using a 'word cloud' (Wordle ${ }^{\mathrm{TM}}$; http://www.wordle.net/). The size of the lettering in the 'word cloud' reflects the frequency with which respondents reported the individual words.

Univariate and multivariate binocular logistic regression analyses were performed to assess factors influencing a clinician's self-reported practices relating to omega-3 fatty acid recommendation for ocular health, and knowledge relating to the biological effects and dietary targets of omega-3 fatty acids. A p-value of less than 0.05 was used to define statistical significance. To quantify participant knowledge about omega- 3 fatty acids, the accuracy of respondents' answers was scored out of five (i.e., one point for each correctly answered question). The five knowledge questions surveyed and the answers that were considered as 'correct' are provided in Table A1. A score of three or more (i.e., $60 \%$ ) was considered a 'pass' for the 'omega-3 knowledge score'.

\section{Results}

\subsection{Participant Demographics}

Of 234 total responses received, 206 responses were included in the analysis. Twenty-eight surveys were excluded because they were either not completed up to the end of Section 3 or were completed by optometrists practicing outside of Australia and New Zealand.

Table 2 summarizes the demographics of participating optometrists. Approximately two-thirds of responses were from optometrists practicing in Australia (64\%) and one-third practicing in New Zealand (36\%). The majority of respondents were endorsed to prescribe ocular therapeutic medications (Australia, 86\%; New Zealand, 91\%).

Most respondents completed their optometry training in Australia or New Zealand (94\%); the remainder completed their degree in the UK, South Africa, or US (and additional competency examinations to practice optometry in Australia or New Zealand). Australian respondents practiced in all 6 states; most were practicing in Victoria (48\%), New South Wales (25\%), and Queensland (12\%). From New Zealand, responses were received from optometrists in all 16 regions except Gisborne, Tasman, Marlborough, West Coast, and Southland. Most New Zealand optometrists practiced in Auckland (35\%), Waikato (14\%), Wellington (13\%), and Hawkes Bay (13\%).

Approximately half of the respondents worked in independent optometric practice (49\%), 30\% worked principally in corporate practice, $11 \%$ in a hospital or public health clinic, and $8 \%$ within academia. The vast majority of respondents $(92 \%)$ selected one or more areas of clinical interest, with $50 \%$ self-declaring interest in DED or ocular surface disease, $26 \%$ in retinal disease, and $8 \%$ in gerontology or aged care. 
Table 2. Summary of participant demographics.

\begin{tabular}{|c|c|}
\hline Characteristic ( $n=206$ for All Categories) & Number of Responses (\%) \\
\hline \multicolumn{2}{|l|}{ Gender } \\
\hline Male & $80(38.8)$ \\
\hline Female & $125(60.7)$ \\
\hline Other/gender diverse & $1(0.5)$ \\
\hline \multicolumn{2}{|l|}{ Age (years) } \\
\hline$<30$ & $91(44.2)$ \\
\hline $31-45$ & $67(32.5)$ \\
\hline $46-60$ & $39(18.9)$ \\
\hline$>60$ & $9(4.4)$ \\
\hline \multicolumn{2}{|c|}{ Completed optometry training in Australia or New Zealand? } \\
\hline Yes & $194(94.2)$ \\
\hline No & $12(5.8)$ \\
\hline \multicolumn{2}{|l|}{ Country of principal practice } \\
\hline Australia & $131(63.6)$ \\
\hline New Zealand & $75(36.4)$ \\
\hline \multicolumn{2}{|l|}{ Therapeutically endorsed } \\
\hline Yes & $180(87.4)$ \\
\hline No & $26(12.6)$ \\
\hline \multicolumn{2}{|l|}{ Principal type of optometric practice } \\
\hline Academic & $16(7.8)$ \\
\hline Corporate & $61(29.6)$ \\
\hline Hospital or public health clinic & $22(10.7)$ \\
\hline Independent & $101(49.0)$ \\
\hline Refractive surgery clinic & $2(1.0)$ \\
\hline Other & $4(1.9)$ \\
\hline \multicolumn{2}{|c|}{$\begin{array}{l}\text { Average hours spent providing patient care as an optometrist } \\
\text { per week }\end{array}$} \\
\hline 0 & $2(1.0)$ \\
\hline $1-10$ & $20(9.7)$ \\
\hline $11-20$ & $23(11.2)$ \\
\hline$>20$ & $161(78.2)$ \\
\hline \multicolumn{2}{|l|}{ Areas of specific clinical interest } \\
\hline Binocular vision & $58(28.2)$ \\
\hline Contact lenses & $96(46.6)$ \\
\hline Diabetes & $65(31.6)$ \\
\hline Dry eye or ocular surface disease & $103(50.0)$ \\
\hline Gerontology or aged care & $17(8.3)$ \\
\hline Glaucoma & $72(35.0)$ \\
\hline Myopia & $120(58.3)$ \\
\hline Paediatrics & $58(28.2)$ \\
\hline Retinal disease & $54(26.2)$ \\
\hline Other & $12(5.8)$ \\
\hline
\end{tabular}

\subsection{Clinical Recommendations Relating to Diet}

As responses from Australian and New Zealand practitioners were similar, pooled data across both locations are presented. Figure 2 summarizes self-reported clinical practice behaviors relating to diet and nutritional supplements. 


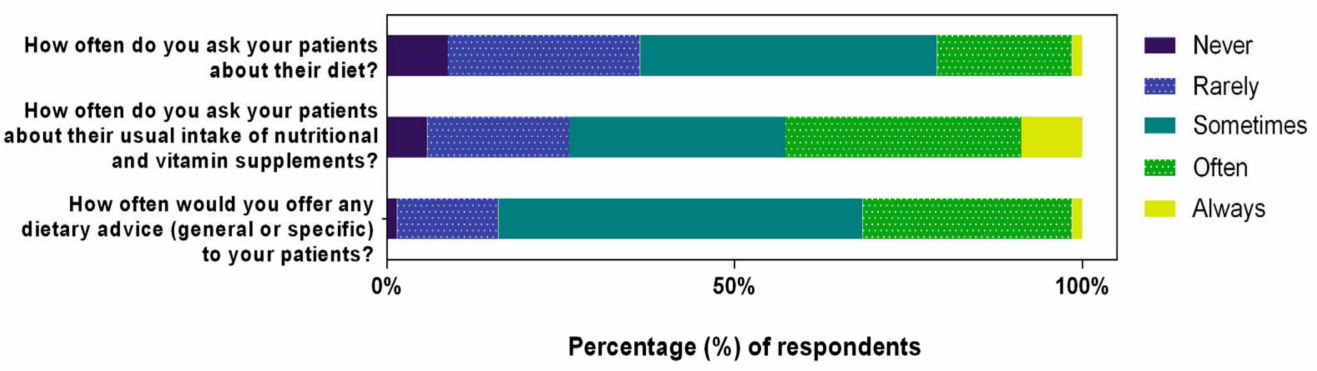

Figure 2. Optometrists' self-reported clinical practices as related to diet and nutritional supplementation. Percentage (\%) of respondents, from $n=206$, who selected each frequency of practice, on a five-step Likert scale.

Of the $91 \%$ of respondents who asked their patients about their diet, $98 \%$ did not use any quantitative tools to survey dietary habits. Three respondents indicated that they used either a food frequency questionnaire $(n=2)$ or an online dietary intake tool $(n=1)$. Optometrists reported more frequently (i.e., often or always) asking their patients about their nutritional supplement intake than about their diet (43\% versus $21 \%$; odds ratio (OR): $2.83,95 \%$ confidence interval, CI: 1.83 to 4.37 ; $p<0.001)$. Approximately one in three optometrists reported often or always $(32 \%)$, and one in two, sometimes (52\%) providing patients with general or specific dietary advice.

Most respondents (79\%) indicated that they recommend the consumption of omega-3 fatty acids to patients, in either supplement form or from food sources, to improve eye health. The remaining (21\%) respondents indicated that they did not make any recommendations to their patients regarding omega-3 fatty acids. None of the respondents recommended that their patients avoid consuming omega-3 fatty acids.

For the 44 respondents who reported not making any recommendations relating to omega- 3 fatty acids, almost half (47\%) indicated that they felt like they did not know enough about omega-3 fatty acids to justify making recommendations. Thirteen respondents felt there was insufficient published research evidence to support omega-3 fatty acid recommendation for eye health, and three indicated that the published evidence they were aware of showed that omega-3 fatty acids were not beneficial for ocular health. Seven respondents either themselves considered or perceived that their patients considered nutritional advice to be outside the scope of optometric practice.

Four respondents indicated that they previously recommended omega-3 fatty acids to their patients, but were no longer doing so. Reason(s) provided included that: they did not see any clinical benefits in their own patients $(n=1)$, recent evidence had changed their opinions $(n=1)$, or they would recommend other forms of therapy (e.g., intense pulsed light therapy for DED) over dietary interventions $(n=2)$. Of the 44 respondents who did not make any recommendations relating to omega-3 fatty acids, 20\% $(n=9)$ indicated recommending supplement formulations based on the results of the Age-Related Eye Disease Studies (AREDS and AREDS II) for their patients with AMD.

Table 3 summarizes the factors that predicted whether optometrists recommended omega- 3 fatty acid consumption to patients to improve their ocular health, from either dietary modification or oral supplementation. In univariate analysis, optometrists were more likely to recommend omega-3 fatty acids if they worked in an independent practice (OR: 4.06, 95\% CI: 1.26-13.06; $p=0.019$ ), had a self-declared clinical interest in DED or ocular surface disease (OR: 4.58, 95\% CI: 2.12-9.91; $p<0.001$ ), or if they recognized that omega-3 fatty acid supplements had potential side effects (OR: $3.94,95 \%$ CI: $1.88-8.25 ; p<0.001)$. In multivariate analysis, both a clinical interest in DED or ocular surface disease (OR: 3.10, 95\% CI: 1.31-7.36; $p=0.010$ ) and recognition that omega-3 fatty acids have side effects (OR: $2.34,95 \%$ CI: $1.05-5.22 ; p=0.037)$ were significant factors in predicting whether omega-3 fatty acids were recommended to improve ocular health. 
Table 3. Factors predicting whether optometrists recommend omega-3 fatty acid consumption (from food sources or supplementation) to improve eye health.

\begin{tabular}{|c|c|c|c|c|}
\hline \multirow{2}{*}{ Factor } & \multicolumn{2}{|c|}{ Univariate Analysis } & \multicolumn{2}{|c|}{ Multivariate Analysis } \\
\hline & OR $(95 \% \mathrm{CI})$ & $p$ Value & OR $(95 \% \mathrm{CI})$ & $p$ Value \\
\hline \multicolumn{5}{|l|}{ Gender $(n=206)$} \\
\hline Male & Ref & & & \\
\hline Female & $0.76(0.38-1.54)$ & 0.450 & & \\
\hline \multicolumn{5}{|l|}{ Age, in years $(n=206)$} \\
\hline$<30$ & Ref & & & \\
\hline $31-45$ & $2.04(0.92-4.49)$ & 0.078 & & \\
\hline$>45$ & $2.34(0.93-5.89)$ & 0.070 & & \\
\hline \multicolumn{5}{|l|}{$\begin{array}{c}\text { Optometric practice } \\
\text { experience, in years }(n=206)\end{array}$} \\
\hline$<10$ years & Ref & & & \\
\hline $11-20$ & $2.31(0.82-6.49)$ & 0.111 & & \\
\hline $21-30$ & $2.10(0.74-5.91)$ & 0.162 & & \\
\hline$>31$ years & $1.63(0.51-5.19)$ & 0.412 & & \\
\hline \multicolumn{5}{|l|}{ Country of practice $(n=206)$} \\
\hline Australia & Ref & & & \\
\hline New Zealand & $1.48(0.72-3.04)$ & 0.288 & & \\
\hline \multicolumn{5}{|l|}{$\begin{array}{l}\text { Therapeutically endorsed } \\
\qquad(n=206)\end{array}$} \\
\hline No & Ref & & & \\
\hline Yes & $0.27(0.06-1.21)$ & 0.087 & & \\
\hline \multicolumn{5}{|l|}{$\begin{array}{c}\text { Principal type of optometric } \\
\text { practice }(n=206)\end{array}$} \\
\hline Academic & Ref & & Ref & \\
\hline Corporate & $1.84(0.57-5.92)$ & 0.306 & $1.87(0.49-7.09)$ & 0.356 \\
\hline Hospital or public health clinic & $1.05(0.28-3.99)$ & 0.943 & $0.96(0.22-4.30)$ & 0.959 \\
\hline Independent & $\begin{array}{c}4.06 \\
(1.26-13.06)\end{array}$ & 0.019 & $2.51(0.67-9.38)$ & 0.171 \\
\hline \multicolumn{5}{|l|}{$\begin{array}{l}\text { Average weekly hours spent } \\
\text { providing patient care as an } \\
\text { optometrist }(n=206)\end{array}$} \\
\hline $1-10$ & Ref & & & \\
\hline $11-20$ & $0.90(0.21-3.94)$ & 0.889 & & \\
\hline$>20$ hours & $0.97(0.30-3.10)$ & 0.959 & & \\
\hline \multicolumn{5}{|l|}{$\begin{array}{l}\text { Self-declared clinical interest } \\
\text { in DED or ocular surface } \\
\text { disease }(n=206)\end{array}$} \\
\hline No & Ref & & & \\
\hline Yes & $4.58(2.12-9.91)$ & $<0.001$ & 3.10 (1.31-7.36) & 0.010 \\
\hline \multicolumn{5}{|l|}{$\begin{array}{l}\text { Self-declared clinical interest } \\
\text { in gerontology or aged care } \\
\qquad(n=206)\end{array}$} \\
\hline No & Ref & & & \\
\hline Yes & $0.62(0.21-1.88)$ & 0.401 & & \\
\hline
\end{tabular}


Table 3. Cont.

\begin{tabular}{|c|c|c|c|c|}
\hline \multirow{2}{*}{ Factor } & \multicolumn{2}{|c|}{ Univariate Analysis } & \multicolumn{2}{|c|}{ Multivariate Analysis } \\
\hline & OR (95\% CI) & $p$ Value & OR (95\% CI) & $p$ Value \\
\hline \multicolumn{5}{|c|}{$\begin{array}{l}\text { Self-declared clinical interest } \\
\text { in retinal disease }(n=206)\end{array}$} \\
\hline No & Ref & & & \\
\hline Yes & 1.07 (0.51-2.27) & 0.857 & & \\
\hline \multicolumn{5}{|c|}{ 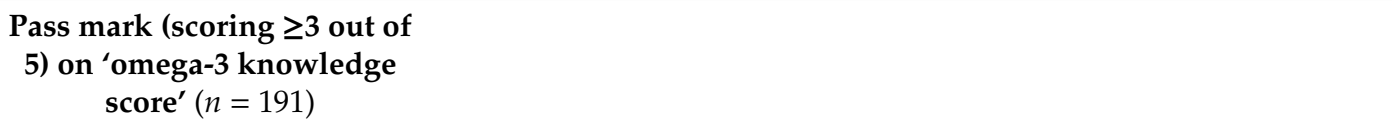 } \\
\hline No & Ref & & & \\
\hline Yes & $1.04(0.37-2.99)$ & 0.936 & & \\
\hline \multicolumn{5}{|c|}{$\begin{array}{l}\text { Recognised that omega-3 } \\
\text { fatty acids have potential } \\
\text { side effects }(n=191)\end{array}$} \\
\hline No & Ref & & Ref & \\
\hline Yes & $3.94(1.88-8.25)$ & $<0.001$ & $2.34(1.05-5.22)$ & 0.037 \\
\hline
\end{tabular}

DED, dry eye disease; OR, odds ratio; Ref, reference.

\subsection{Recommendations Relating to Omega-3 Fatty Acids in Age-Related Macular Degeneration (AMD)}

Figure 3A summarizes the self-reported practice behaviors of optometrists relating to omega-3 fatty acid intake, through either diet or supplementation, as a component of clinical management for people with AMD. Overall, $68 \%$ of optometrists indicated recommending omega- 3 rich foods for AMD (Figure 3B). Almost all (95\%) recommended fish or non-fish seafood as a food source. Almost $80 \%$ of optometrists who recommended fish or seafood specified the preferred frequency of consumption, and this was most commonly two to four servings per week (Figure 3C). Two-thirds of optometrists who recommended omega-3 rich foods for AMD suggested nuts and seeds $(63 \%)$, and $40 \%$, vegetables or fruits.

Participants who indicated recommending omega-3 supplements were invited to detail the specific recommendation(s) given to their patients (such as dose, frequency, brand). Figure 3D provides a visual representation of these free-text responses received from 80 of the 132 practitioners $(61 \%)$, constructed using a 'word cloud'. Supplements broadly based on the formulation in the AREDS studies [38] (Macutec (Stiltec Pty Ltd, Queensland, Australia), Macuvision (Blackmores, New South Wales, Australia), or MD Eyes (MD EyeCare, Queensland, Australia)) were listed by $21 \%$ of optometrists who provided free-text responses $(n=17)$. About one-third of respondents $(29 \%)$ provided specific dosages in their recommendations $(n=23)$, and these ranged from $250 \mathrm{mg}$ to $5000 \mathrm{mg}$ of omega- 3 fatty acids per day (Median [Inter-quartile range, IQR]: 2000 [1000-3000] mg/day). Twelve percent of respondents $(n=10)$ indicated that they do not make specific recommendations relating to the brand or dosage of omega-3 supplement, and $11 \%$ percent indicated that they would advise their patients to consult either a pharmacist or a general practitioner for advice relating to specific supplementation products and the dosage. 
(A) Frequency of recommendation
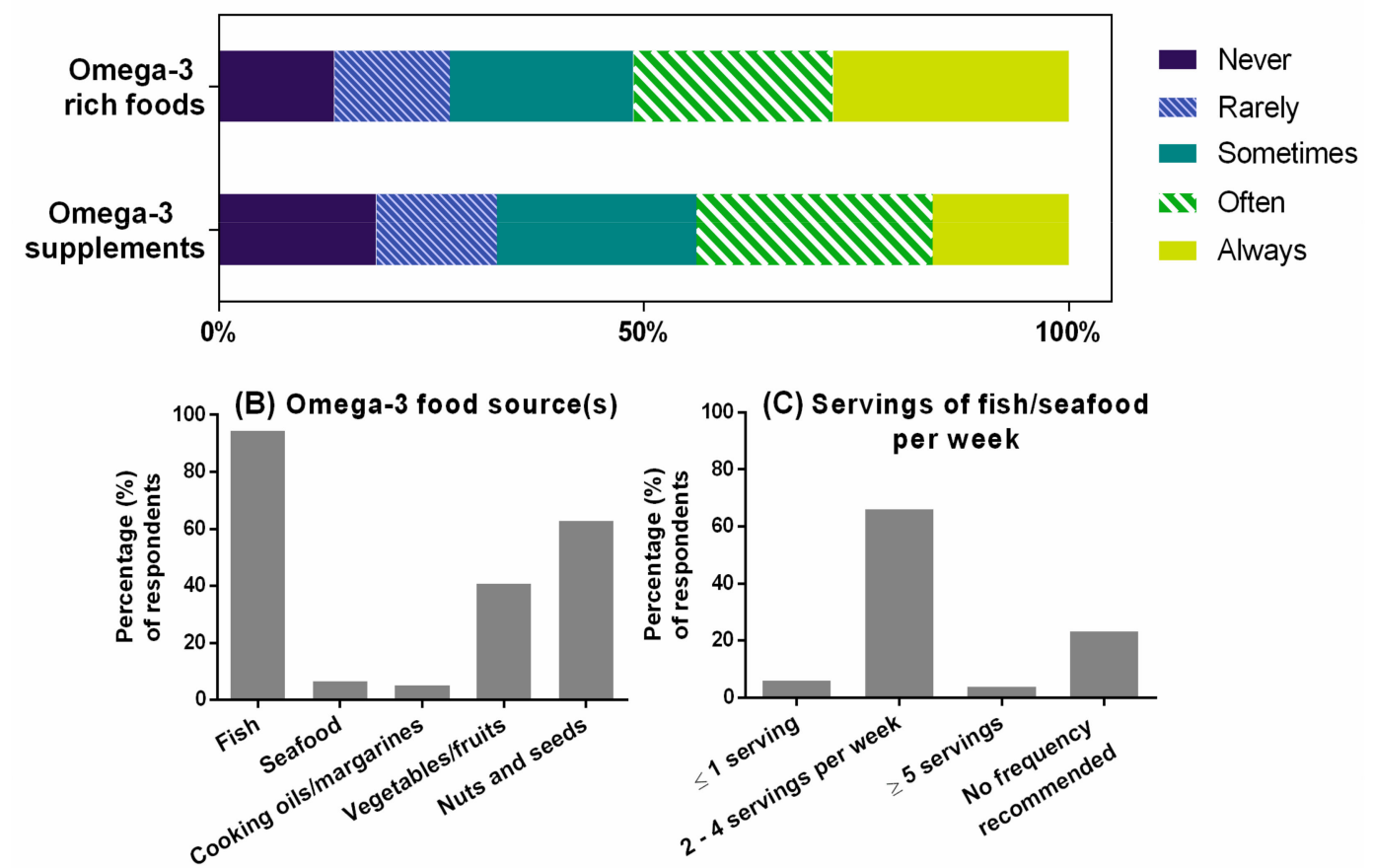

(D) Omega-3 supplement recommendations

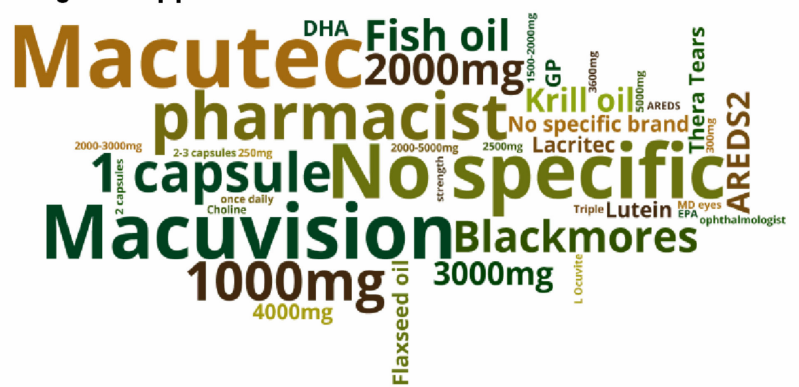

Figure 3. Optometrists' self-reported clinical practices as related to omega-3 fatty acid intake as a component of AMD management. (A) Self-reported frequency of recommending omega-3-rich foods and nutritional supplements. Percentage of respondents shown from $n=162$ who indicated recommending omega-3 fatty acids for AMD. (B) Omega-3 food sources(s) recommended by respondents. Percentage shown from $n=140$ who indicated recommending omega-3-rich foods. (C) Recommended ideal frequency for patients to consume marine-based (long-chain) omega-3-containing foods. Percentage shown from $n=133$ who indicated recommending fish or seafood as omega-3 food sources in (B). (D) Word-cloud representation of specific recommendations for omega-3 supplementation (based on $n=80$ responses from the 132 participants who indicated recommending omega- 3 supplements).

\subsection{Recommendations Relating to Omega-3 Fatty Acids in Dry Eye Disease (DED)}

Figure 4A summarizes the self-reported practice behaviors of optometrists who recommended omega-3 fatty acids as a component of DED management. Compared with AMD (68\%), a higher proportion of respondents (78\%) indicated recommending omega-3 fatty acids from food sources or supplements to manage DED. Almost all ( $>99 \%)$ of respondents who made this recommendation considered omega-3 fatty acids to be appropriate for evaporative and/or mixed etiologies of DED (Figure 4B). Only one practitioner indicated recommending omega-3 fatty acids specifically for the aqueous-deficient DED subtype. Practitioners were less likely to recommend omega- 3 fatty acids to patients with mild, compared to moderate or severe forms of, DED (Figure 4C, OR: 0.24, 95\% CI: 0.16 to $0.37 ; p<0.001$ ). 
(A) Frequency of recommendation
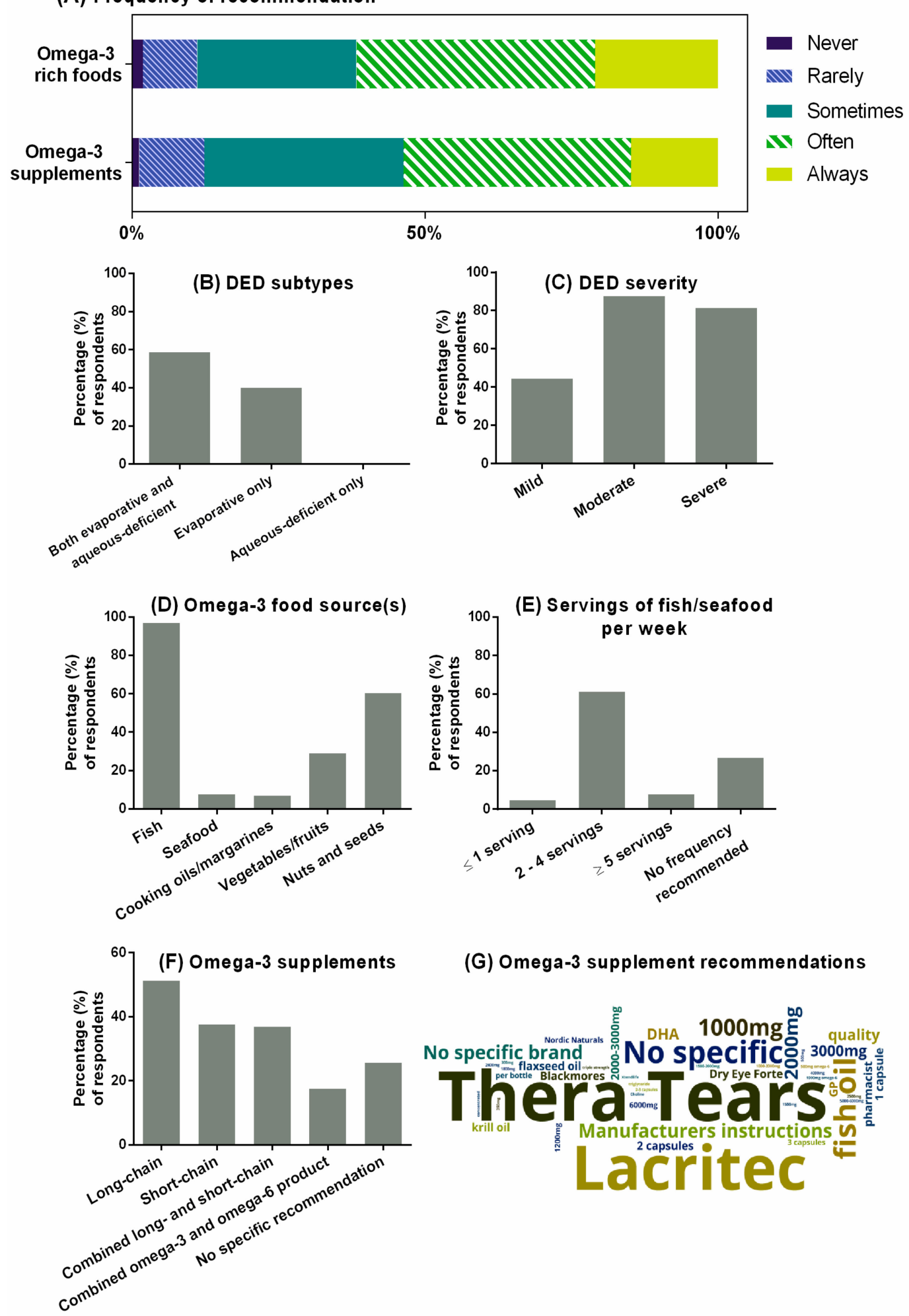

(G) Omega-3 supplement recommendations

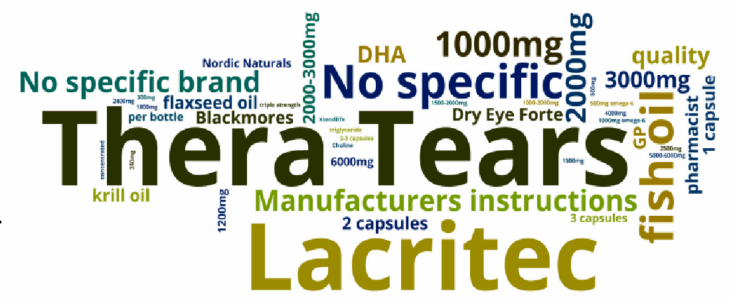

Figure 4. Optometrists' self-reported clinical practices as related to omega-3 fatty acids for managing DED. (A) Self-reported frequency of recommending omega-3-rich foods and nutritional supplements. Percentage of respondents shown from $n=162$ who indicated recommending omega- 3 fatty acids for DED, (B) DED subtypes, and (C) severities that participants self-reported making recommendations for omega-3 fatty acids (in either food or supplement forms). Percentages shown from $n=162$. (D) Type of omega-3 food source(s) recommended. Percentage shown from $n=159$ who indicated recommending 
omega-3-rich foods. (E) Recommended ideal frequency for patients to consume marine-based (long-chain) omega-3-rich foods. Percentages shown from $n=154$ who indicated recommending fish or seafood as omega-3 food sources in (e). (F) Type of oral omega-3 supplements recommended. Percentages shown from $n=160$ who indicated recommending omega-3 supplements. (G) Word-cloud representation of specific recommendations for omega- 3 supplementation (based on $n=105$ responses from the 160 participants who indicated recommending omega-3 supplementation).

Self-reported clinical recommendations relating to dietary sources of omega-3-rich foods and frequency of intake in DED were similar to those for AMD (Figure 4D). Of the 77\% of optometrists who recommended for patients to increase their intake of foods rich in omega-3 fatty acids to improve their DED, almost all (97\%) specified either fish or non-fish seafood sources, most commonly between two and four servings per week (Figure 4E). Over half of respondents recommended nuts and seeds $(60 \%)$, and one in three indicated value in consuming vegetables or fruits to obtain omega-3 fatty acids.

Oral omega-3 supplements were recommended by $78 \%$ of optometrists for managing DED (Figure 4F). The most frequently recommended forms were long-chain omega-3 fatty acids from marine-based sources ( $40 \%$ of all optometrists), short-chain omega- 3 from plant-based sources ( $29 \%$ of all optometrists), and combined long- and short-chain omega- 3 fatty acids ( $29 \%$ of all optometrists). Omega- 3 and omega- 6 combination products were recommended by $14 \%$ of optometrists for DED.

Figure 4G shows a 'word cloud' representation of the free-text responses from the 105 of 160 practitioners $(65 \%)$ who provided specific recommendations regarding omega-3 supplements for DED. As represented by the size of the lettering, Thera Tears (Akorn Consumer Health, MI, USA) and Lacritec (Stiltec Pty Ltd, QLD, Australia) were the two most frequently recommended commercial brands, listed by $17 \%$ and $15 \%$ of respondents, respectively. About one-third of respondents provided specific omega-3 dosage recommendations for DED (31\%), which ranged from $250 \mathrm{mg}$ to $6000 \mathrm{mg}$ per day (median [IQR]: 2000 [1000-2750] mg per day), and 10\% $(n=10)$ of respondents advised their patients to consult either the instructions on the supplement bottle or the advice of a pharmacist.

\subsection{Practitioner Knowledge of Omega-3 Fatty Acids}

Half of the respondents (50\%) were not aware of a difference between the biological effects of plant-based (short-chain) and marine-based (long-chain) omega-3 fatty acids. About one-third (31\%) correctly considered plant-based omega- 3 fatty acids to have less, and $12 \%$ considered plant-based omega-3 fatty acids to have greater, biological effect than marine-based omega- 3 fatty acids when consumed at the same dose. Just over half (51\%) of respondents considered omega- 3 fatty acids to be mostly anti-inflammatory, $15 \%$ of optometrists recognized that omega- 3 fatty acids are always anti-inflammatory, and $42 \%$ of optometrists correctly considered omega- 6 fatty acids to be mostly pro-inflammatory. The perceived ideal ratio of omega- 6 to omega- 3 in the human diet was most frequently selected as 1 to 4 ( $27 \%$ of optometrists), $16 \%$ of respondents correctly selected the ideal ratio to be 4 to 1 , and $39 \%$ of optometrists were unsure of the ideal ratio.

From a forced-choice list of five options ranging from $150 \mathrm{mg} /$ day to $1500 \mathrm{mg} /$ day, $65 \%$ of respondents nominated a daily recommended dietary target of long-chain omega-3 fatty acids (the remaining respondents selected 'don't know'). The most common daily targets selected were $1000 \mathrm{mg}$ per day (24\% of optometrists) and $1500 \mathrm{mg}$ per day (17\% of optometrists). One in 11 respondents correctly selected the ideal approximate target of $500 \mathrm{mg} /$ day for adults. About half of respondents (52\%) considered there to be a safety limit for daily omega-3 fatty acid consumption; the perceived limit selected by respondents encompassed a 20-fold dose range. From the four multiple choice options offered, $500 \mathrm{mg}$ per day was considered the upper limit by $4 \%$ of all optometrists, $1500 \mathrm{mg}$ per day by $15 \%$ of optometrists, $3000 \mathrm{mg}$ per day by $18 \%$ of optometrists, and $5000 \mathrm{mg}$ per day by $8 \%$ of optometrists.

Over half (53\%) of respondents believed that omega- 3 fatty acids have potential side effects. Based on multiple-choice options (see Table 1), these were most commonly believed to be gastric reflux 
$(37 \%)$, nose bleeds $(23 \%)$, and bloating (11\%). Forty-six percent of respondents considered possible contraindications to use before recommending omega-3 fatty acids. In open-text boxes, the most commonly suggested contraindications were concurrent anticoagulant medications $(26 \%)$, allergies to fish/seafood (12\%), or a scheduled surgical procedure (3\%). Five percent of respondents indicated they would ask the patient to consult their general practitioner or specialist prior to commencing oral omega-3 supplementation.

The level of respondents' knowledge of omega-3 fatty acids was assessed using an 'omega-3 knowledge score', derived from five knowledge-specific questions in the survey (see Table A1). A 'pass' was considered a score of three or more out of five (i.e., at least $60 \%$ ). Using this criterion, in both univariate and multivariate analysis (Table 4), optometrists with a self-reported clinical interest in DED or ocular surface disease were more knowledgeable about omega-3 fatty acids (OR: $2.97,95 \% \mathrm{CI}$ : 1.09 to $8.11 ; p=0.034$ ) relative to those without such interests. Compared with respondents working in academia, those who were based principally in a corporate practice setting had a lower omega-3 knowledge score (OR: $0.080,95 \%$ CI: 0.008 to $0.086 ; p=0.037$ ).

Table 4. Predictive factors for a 'pass' mark on the omega-3 knowledge score, relating to the accuracy of practitioners' general knowledge about omega-3 fatty acids.

\begin{tabular}{|c|c|c|c|c|}
\hline \multirow{2}{*}{$\begin{array}{c}\text { Factors ( } n=206 \text { for All } \\
\text { Categories) }\end{array}$} & \multicolumn{2}{|c|}{ Univariate Analysis } & \multicolumn{2}{|c|}{ Multivariate Analysis } \\
\hline & OR $(95 \% \mathrm{CI})$ & $p$ Value & OR $(95 \% \mathrm{CI})$ & $p$ Value \\
\hline \multicolumn{5}{|l|}{ Gender } \\
\hline Male & Ref & & & \\
\hline Female & $1.35(0.55-3.34)$ & 0.511 & & \\
\hline \multicolumn{5}{|l|}{ Age (years) } \\
\hline$\leq 30$ & Ref & & & \\
\hline $31-45$ & $1.93(0.68-5.50)$ & 0.219 & & \\
\hline$>45$ & $2.41(0.81-7.15)$ & 0.113 & & \\
\hline \multicolumn{5}{|l|}{$\begin{array}{c}\text { Optometric practice experience } \\
\text { (years) }\end{array}$} \\
\hline$\leq 10$ & Ref & & & \\
\hline $11-20$ & $1.49(0.48-4.64)$ & 0.492 & & \\
\hline $21-30$ & $1.66(0.53-5.21)$ & 0.384 & & \\
\hline$>31$ & $1.52(0.40-6.04)$ & 0.549 & & \\
\hline \multicolumn{5}{|l|}{ Country of practice } \\
\hline Australia & Ref & & & \\
\hline New Zealand & $2.04(0.86-4.83)$ & 0.106 & & \\
\hline \multicolumn{5}{|l|}{ Therapeutically endorsed } \\
\hline No & Ref & & & \\
\hline Yes & $0.55(0.18-1.62)$ & 0.276 & & \\
\hline \multicolumn{5}{|l|}{$\begin{array}{l}\text { Principal type of optometric } \\
\text { practice }\end{array}$} \\
\hline Academic & Ref & & & \\
\hline Corporate & $0.07(0.01-0.76)$ & 0.029 & $0.08(0.01-0.86)$ & 0.037 \\
\hline Hospital or public health clinic & $1.25(0.25-6.29)$ & 0.787 & $1.68(0.31-9.02)$ & 0.544 \\
\hline Independent & $0.77(0.19-3.06)$ & 0.710 & $0.72(0.18-2.94)$ & 0.645 \\
\hline \multicolumn{5}{|l|}{$\begin{array}{c}\text { Average weekly hours spent } \\
\text { providing patient care as an } \\
\text { optometrist (years) }\end{array}$} \\
\hline $1-10$ & Ref & & & \\
\hline $11-20$ & $0.85(0.11-6.70)$ & 0.877 & & \\
\hline$>20 \mathrm{~h}$ & $1.24(0.27-5.81)$ & 0.783 & & \\
\hline
\end{tabular}


Table 4. Cont.

\begin{tabular}{|c|c|c|c|c|}
\hline \multirow{2}{*}{$\begin{array}{l}\text { Factors ( } n=206 \text { for All } \\
\text { Categories) }\end{array}$} & \multicolumn{2}{|c|}{ Univariate Analysis } & \multicolumn{2}{|c|}{ Multivariate Analysis } \\
\hline & OR $(95 \%$ CI) & $p$ Value & OR $(95 \%$ CI) & $p$ Value \\
\hline \multicolumn{5}{|c|}{$\begin{array}{l}\text { Self-declared clinical interest in } \\
\text { DED or ocular surface disease }\end{array}$} \\
\hline No & Ref & & & \\
\hline Yes & $2.84(1.12-7.20)$ & 0.028 & $2.97(1.09-8.12)$ & 0.034 \\
\hline \multicolumn{5}{|c|}{$\begin{array}{l}\text { Self-declared clinical interest in } \\
\text { gerontology or aged care }\end{array}$} \\
\hline No & Ref & & & \\
\hline Yes & $0.54(0.14-2.08)$ & 0.372 & & \\
\hline \multicolumn{5}{|c|}{$\begin{array}{l}\text { Self-declared clinical interest in } \\
\text { retinal disease }\end{array}$} \\
\hline No & Ref & & & \\
\hline Yes & $1.45(0.51-4.10)$ & 0.489 & & \\
\hline \multicolumn{5}{|c|}{$\begin{array}{l}\text { Omega-3 fatty acids (from diet } \\
\text { or supplementation) } \\
\text { recommended in their practice } \\
\text { for improving ocular health }\end{array}$} \\
\hline No & Ref & & & \\
\hline Yes & $1.04(0.37-2.99)$ & 0.936 & & \\
\hline
\end{tabular}

\subsection{Sources of Evidence and Information}

Figure 5 summarizes the sources of evidence and information that respondents indicated had informed their current clinical decision-making relating to omega- 3 fatty acids. Continuing education conference presentations and articles were the major information sources followed by respondents' university education and personal clinical experiences. Two in five optometrists (40\%) indicated using published primary research papers and/or systematic reviews to guide their clinical decision-making in this area of practice.

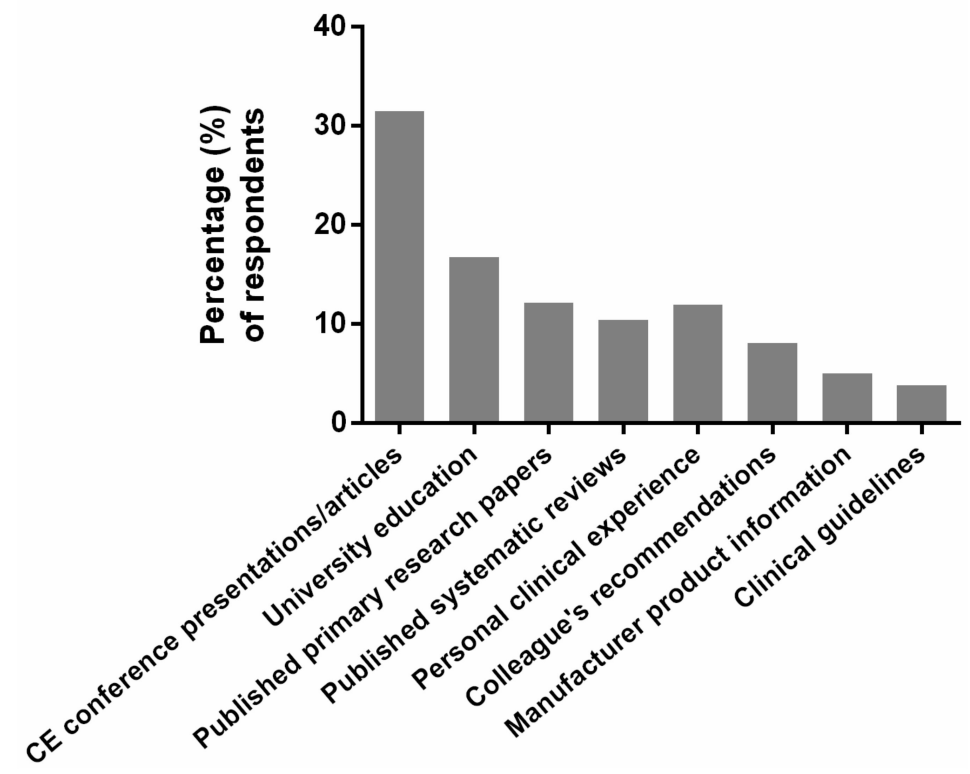

Figure 5. Percentage of optometrists who selected each information and/or evidence source (with no limit on the number of sources able to be selected) as informing their clinical decision-making regarding omega-3 fatty acids. CE, continuing education. 


\section{Discussion}

This study describes the self-reported clinical practices and opinions of Australian and New Zealand optometrists, as related to omega- 3 fatty acids and eye health. To our knowledge, this is the first study to consider clinicians' awareness and routine practices relating to omega-3 fatty acids in primary health care. The chosen focus on omega-3 fatty acids for this survey was based on their reported potential to improve outcomes in certain chronic ocular conditions, such as DED and AMD. The current findings provide new insights into optometrists' understanding of current research evidence relating to omega-3 fatty acids in the context of eye health, and their self-reported application of this knowledge in practice. Furthermore, this survey considered the sources of information and evidence used to guide optometrists' clinical decision-making as a foundation for informing the optimal mode(s) of delivering future education programs relating to nutrition in eye care practice.

\subsection{General Recommendations of Optometrists Relating to Diet and Nutrition}

This survey, which was made available to an estimated 6500 practicing optometrists via professional optometry networks in Australia and New Zealand, received responses that were considered representative of the major regions in both countries. About half of respondents described their principal practice setting as independent (49\%), which indicates a possible over-representation of responses received from independent practices compared to corporate or public health practices (local healthcare workforce data suggest $\sim 30 \%$ optometry registrants practice in independent-settings practice [39]). Globally, there is substantial variation in optometric scope of practice. In some countries, such as France and Japan, optometrists are restricted to providing optical corrections using spectacles and/or contact lenses [40,41]. In contrast, in some states of the US and Canada, optometric practice includes performing refractive surgery procedures and minor ocular surgery [42-44]. The role of optometrists in Australia and New Zealand includes the independent diagnosis and management of ocular disorders relating to visual function and eye health $[36,43]$. In addition, optometrists who hold therapeutic medicine endorsement are permitted to prescribe topical, and in New Zealand oral, medications for managing eye disease. Overall, most survey respondents were qualified to prescribe topical ophthalmic therapeutic medications at a minimum (Australia, 86\%; New Zealand, 91\%). These proportions are higher than the documented percentage of therapeutically endorsed practitioners in both countries (Australia 63\%; New Zealand 75\%) [43,45]; this may be due to a self-selection bias based on clinical skill or interest, and/or that the survey responses were generally from a younger cohort of optometrists ( $44 \%$ under 30 years of age, compared with $26 \%$ of all Australian optometrists being under the age of 30 [45]). Since 2013, all entry-level optometrists from accredited programs in Australia and New Zealand have graduated with therapeutic prescribing rights [36].

Optometrists, as major providers of primary eye care, are ideally placed to ask patients about their diet and to offer evidence-based advice about nutrition-based strategies for reducing the risk and/or progression of ocular disease. In a previous survey-based study, it was reported that two in five patients attending for optometric care in Australia expected their optometrists to ask them about their diet and/or nutritional supplement intake, although only one in five recalled being asked about these factors when attending an optometric consultation [37]. In the present study, most (64\%) respondents self-reported generally (i.e., sometimes, often, or always) enquiring about their patients' diet and/or their routine intake of nutritional or vitamin supplements $(74 \%)$. These values are similar to findings reported in a cohort survey undertaken five years ago, which found that $62 \%$ of Australian optometrists self-reported counseling their patients about their diet, and 55\% self-reported providing advice about nutritional supplementation [35].

\subsection{Recommendations Relating to Omega-3 Fatty Acids for Managing AMD}

Over $50 \%$ of respondents indicated that they would frequently recommend for their AMD patients to increase their intake of omega-3 rich foods. This is comparable to a previous survey, conducted 
in the UK, which found that about half of eye care professionals (optometrists or ophthalmologists) reported frequently recommending eating oily fish at least twice per week to individuals with AMD and/or individuals considered to be at risk of AMD [34].

Several prospective cohort studies have associated higher intakes of foods containing long-chain omega-3 fatty acids with a reduced risk of AMD progression [31,46]. The Blue Mountains Eye Study found that eating oily fish at least once per week, compared with less than once per week, was associated with a lower risk of developing early-stage AMD [47]. Systematic reviews, synthesizing results from primary research studies, have also found that eating approximately two servings of oily fish per week is associated with a reduced risk of both developing early AMD and progressing to late-stage disease $[48,49]$. Most optometrists who recommended consumption of fish or seafood, recommended an intake frequency of two or more servings per week, consistent with current evidence [48].

With respect to omega- 3 fatty acid supplementation, $62 \%$ of respondents reported recommending either plant- or marine-based supplements for AMD management. Although it might be argued that a person's diet can be augmented through supplementation if adequate levels of certain nutrients are not being obtained from food sources, the current best-available evidence does not support omega-3 oral supplements for preventing or slowing the progression of AMD [32]. In contrast to many epidemiological studies on diet, a Cochrane systematic review, which combined findings from two randomized controlled trials, reported that long-chain omega-3 supplementation for a period of up to five years did not reduce the development of vision loss or the risk of progression to advanced AMD [32]. Furthermore, in the AREDS II trial, the addition of xanthophyll carotenoids (lutein and zeaxanthin) and omega-3 fatty acids to the original high-dose antioxidant AREDS formulation did not further reduce the risk of progression to late-stage AMD relative to the original formulation [50]. This finding is in contrast to observational evidence that has reported the potential benefit of high dietary intakes of lutein and zeaxanthin for lowering the overall risk of developing late-stage AMD [51].

The absorption of EPA and DHA from nutritional supplementation is influenced by the formulation, chemical preparation, and a person's background dietary fats [52,53]. Phospholipid and triglyceride forms are considered to have superior bioavailability compared to ethyl ester forms [53]. Nonetheless, nutritional supplements do not contain the full spectrum of nutrients present in whole foods. Consuming a supplement, rather than whole foods, may limit key interactions between the fatty acids and other nutrient components that could contribute towards the retinoprotective effect evident with omega-3 rich diets [54]. In the context of AMD, omega-3 supplements are, thus, not an equivalent substitute for omega- 3 fatty acids from dietary sources. Our findings suggest that many optometrists may not be aware of this subtle, but important, distinction.

\subsection{Recommendations Relating to Omega-3 Fatty Acids for Managing DED}

About $80 \%$ of respondents reported recommending omega-3 fatty acids, in either diet or supplement form, for DED management. This proportion is comparable to previously reported values of $70 \%$ of Australian optometrists [55] and $80 \%$ of New Zealand optometrists in surveys of DED practice patterns [56]. In the present study, we found more respondents reported recommending omega-3 fatty acids for DED management than for AMD. This is perhaps not surprising given that the anti-inflammatory effects of omega-3 fatty acids are widely promoted, and several clinical trials have demonstrated favorable results supporting the use of omega-3 supplements for improving clinical outcomes in DED [25].

Although the pathogenesis of DED is unclear, tear instability, tear hyperosmolarity, and neuro-sensory abnormalities are understood to contribute to a vicious cycle of inflammation that perpetuates on the ocular surface [16]. The primary etiological factor is considered to differ between the two main DED subtypes: the evaporative form of DED, which is frequently caused by meibomian gland dysfunction, and aqueous-deficient DED, which is often associated with aging and systemic autoimmune conditions [15]. Almost all the practitioners who reported recommending omega-3 fatty acids for DED indicated doing so for managing evaporative or mixed DED, rather than for 
aqueous-deficient DED. The rationale for this practice may relate to the potential for systemic fatty acid consumption to modify lipid production and regulate the lipid-secreting meibomian glands, both of which may be beneficial in evaporative DED [57,58]. However, it may be advisable to exercise caution in interpreting the result for aqueous-deficient DED, on account of the relative rarity of this subtype in an unmixed form, without an overlay of the more prevalent evaporative form [56]. Notwithstanding these practice patterns, the anti-inflammatory benefits conferred by omega- 3 fatty acids are not restricted to improving tear-lipid dysfunction, as aqueous-deficient DED may be associated with an immune-mediated inflammatory response [16]. Notably, a recent Cochrane systematic review found that in DED, long-chain omega-3 supplements, compared to placebo, increased aqueous tear production and improved tear osmolarity, both of which are compromised in aqueous-deficient DED [25].

Our study established that practitioners are less likely to report recommending omega-3 fatty acids for milder forms of DED. This trend has been reported in previous evaluations of self-reported practices relating to recommending omega-3 fatty acids for DED, by eye care practitioners in New Zealand, Australia, and the UK [55,56]. It is unclear why this practice behavior exists given a lack of specific evidence to support this approach. In the DED staged management and therapy algorithm published in the 2017 Tear Film and Ocular Surface Society (TFOS) International Dry Eye Workshop II report (TFOS DEWS II), education regarding potential dietary modification (including oral essential fatty acid supplementation) is listed as a treatment approach for all DED stages, and not limited to only moderate or severe disease [59]. Whether perceived cost implications for patients at an early disease stage plays a role in this decision-making is not known.

Respondents indicated recommending a variety of daily omega-3 fatty acid dosages for managing DED, ranging from $250 \mathrm{mg}$ to $6000 \mathrm{mg}$ per day (median [IQR]: 2000 [1000-2750] mg/day). Published guidelines exist with regard to the optimal dose of omega-3 fatty acids for several other health conditions. For example, the American Heart Association recommends $4000 \mathrm{mg}$ EPA, or combined EPA and DHA, per day for reducing systemic triglycerides in cases of hypercholesterolemia [60]. The International Society for Nutritional Psychiatry Research recommends 1000 to $2000 \mathrm{mg}$ of EPA per day for treating major depressive disorders [61]. There are currently no formal recommendations for the optimal supplement dosage that may provide clinical benefit in ocular conditions.

Randomized controlled trials (RCTs), comparing the efficacy of long-chain omega-3 fatty acids relative to placebo or to no intervention for treating DED, have adopted a wide range of dosages, varying across a 20-fold range, from $135 \mathrm{mg}$ to $3000 \mathrm{mg}$ of combined EPA and DHA per day [25]. This large dosing range could contribute to the apparently contrasting outcomes observed in different intervention trials $[20,21,23]$. Factors that may contribute to heterogeneity in the reported effect estimates of omega-3 supplement clinical efficacy for treating DED include: differences in study design, population selection, and the choice of outcome measures. There is also lack of certainty in the literature with regard to the optimal form of the long-chain omega- 3 fatty acid supplements, which exist in triglyceride, ethyl ester, or phospholipid forms, and the optimal ratio of EPA to DHA for DED treatment [25]. Compounding these issues is the current lack of consensus on the most appropriate omega-3 fatty acid-prescribing protocol, specifically as related to dose, treatment duration, and composition, to achieve the most clinical benefit [59]. Of specific relevance to DED, there is emerging evidence to suggest that topical omega-3 fatty acid supplementation also may have a role in modulating ocular surface inflammation $[62,63]$.

The two commercially available formulations reported to be most frequently recommended by survey respondents were Thera Tears ${ }^{\mathrm{TM}}$ (dosage recommended by manufacturer: three capsules daily, each containing $450 \mathrm{mg}$ EPA, $300 \mathrm{mg}$ DHA, $1337.5 \mathrm{mg}$ ALA, and 183 IU vitamin E as an antioxidant) and Lacritec ${ }^{\mathrm{TM}}$ (dosage recommended by manufacturer: three capsules daily for six weeks, and two capsules daily thereafter, each capsule containing $134 \mathrm{mg}$ EPA, $66.8 \mathrm{mg}$ DHA, $58.5 \mathrm{mg}$ oleic acid, $58.5 \mathrm{mg}$ linoleic acid (LA), $192 \mathrm{mg}$ linolenic acid, $434 \mathrm{mg}$ Borago officinalis seed oil fixed, and $93.5 \mathrm{mg}$ gamma-linolenic (GLA) acid). In addition to omega-3 fatty acids, Lacritec contains short-chain omega- 6 fatty acids. Approximately one in five optometrists reported recommending 
combined omega-3 and omega-6 supplements for managing DED. While eicosanoids derived from the metabolism of the long-chain omega- 6 fatty acid, AA, are pro-inflammatory, dietary intake of the short-chain omega-6, GLA, and its precursor, LA, can yield anti-inflammatory effects by acting as precursors to the eicosanoid prostaglandin-E1 (PGE1) [64]. The potential effects of omega-6 fatty acids on ocular surface inflammation are, therefore, complex.

The US Women's Health Study found an association between a higher ratio of dietary omega-6 to omega-3 and an elevated risk of DED [19]. A recent cross-sectional study reported that relatively high omega-3 consumption and moderate omega- 6 consumption were protective against meibomian gland dysfunction in postmenopausal women [65]. However, several RCTs assessing the efficacy of GLA and LA for alleviating ocular surface inflammation have reported inconsistent effects $[25,66,67]$. A recent Cochrane systematic review found that relative to placebo, combined omega-3 and omega- 6 fatty acid supplements had no benefit on aqueous tear production or ocular surface staining. Although the pooled effect estimate indicated a possible improvement in tear stability with this intervention, the change was not considered clinically meaningful [25].

Baseline dietary omega-3 fatty acid intake is another important consideration for identifying patient populations likely to benefit from enhancing their omega-3 fatty acid intake. Supplementation in individuals already achieving sufficient essential fatty acid levels through their diet would not be expected to demonstrate the same biological response as in those who are deficient [68]. While $99 \%$ of surveyed optometrists in this study reported offering dietary advice to their patients, almost none used quantitative tools to survey their patients' existing dietary habits. Techniques that can be used to estimate omega-3 intake include fatty acid assays from blood samples, although testing tends to be invasive, relatively costly and may not be readily accessible to all clinicians, and collection of short-term dietary records, which can be time consuming and, thus, not ideally suited for use in clinical settings. To overcome these barriers, simple food frequency tools may be of value for providing a rapid, non-invasive estimation of an individual's omega-3 intake, and for informing clinical recommendations regarding the potential benefit, or otherwise, of supplementation or dietary modification [69].

\subsection{Knowledge of the Potential Benefits and Risks of Omega-3 Fatty Acids}

It has been estimated that in Australia, 80\% of adults may not be meeting the suggested dietary intake of long-chain omega-3 fatty acids [9], which, as recommended by the National Health and Medical Research Council (NHMRC) is $430 \mathrm{mg}$ per day for female adults and $610 \mathrm{mg}$ per day for male adults [70]. Almost half (46\%) of practitioners surveyed recommended for their patients to consume between two and four servings of fish or non-fish seafood per week to improve ocular health. However, less than one in 10 respondents estimated the closest to ideal approximate adult dietary target of marine-based omega-3 fatty acids as $500 \mathrm{mg} /$ day (which approximates to consuming two servings of oily fish per week). Furthermore, less than one-third of respondents were aware that short-chain omega-3 fatty acids, obtained from plant-based sources, are less directly biologically active than long-chain omega-3 fatty acids [71,72]. This disparity highlights a potential target area for professional education to raise awareness about the relative biological efficacy of different food sources.

High-dose omega-3 fatty acids, >2000 mg per day, tend to be safe and well tolerated but are not without potential adverse effects. The most common side effects are gastrointestinal (e.g., nausea, bloating), dermatological (e.g., skin itchiness), and hematological (e.g., anticoagulatory effects). Several studies examining the safety profile of omega-3 fatty acids, dosed at up to $4000 \mathrm{mg}$ per day, have concluded that supplementation is generally well tolerated and that associated adverse events are unlikely to be of clinical significance [60,61,73-75]. Over half of survey respondents (53\%) reported taking the safety profile of omega- 3 fatty acids (i.e., side effects and contraindications) into consideration when making clinical recommendations. Optometrists who declared a clinical interest in DED or ocular surface disease were twice as likely to recommend omega-3 fatty acids to their patients (95\% CI: 1.05-5.2) than those without such interests. Interestingly, respondents who recognized that omega-3 fatty acids have potential side effects were approximately four times more likely to recommend their 
use. While this might initially seem counterintuitive, it may be a testament to optometrists being cautious prescribers, and a likelihood that clinicians with greater awareness about the safety profile of omega-3 fatty acids are also more likely to be knowledgeable about their benefits. More extensive knowledge may bring about greater confidence in making clinical dietary recommendations. This is corroborated by the finding that survey respondents who declared an interest in DED or ocular surface disease were three times more likely to successfully demonstrate their knowledge about the underlying biological effects and dietary targets of omega-3 fatty acids than those who failed to correctly answer $60 \%$ or more of the relevant knowledge-focused questions.

\subsection{Sources of Information and Evidence Used to Guide Clinical Decision Making}

Four in five respondents selected continuing education conferences and/or articles as the main source of information used to guide their clinical decision making about omega-3 fatty acids. Two in five respondents indicated that they source primary research articles and/or systematic reviews for advice.

The importance of evidence-based practice is well recognized in both optometric training and practice [76]. A previous study reported that while attitudes towards evidence-based practice were generally positive among eye care practitioners, a key barrier was a lack of clinician time to access and appraise large volumes of research evidence [76]. Specific barriers that appear to challenge the adoption of best practice relating to nutrition and dietary recommendations in practice include the apparently conflicting results from different studies, a perception from some clinicians that nutritional advice is outside the optometric scope of practice, and a paucity of available clinical tools for quantifying diet in clinical practice.

A number of recent initiatives have sought to support optometrists in making evidence-based dietary recommendations that are relevant to eye health. Optometry Australia's 2019 AMD Clinical Practice Guide recommends that optometrists inform patients about how AMD risk can be modified by diet and other lifestyle factors, such as smoking [77]. With respect to DED, the TFOS DEWS II reports provide a peer-reviewed, open-access summary of the current scientific evidence, based on expert consensus [78]. In the TFOS DEWS II report, providing patient education about potential dietary modifications (including oral omega-3 supplementation) is listed within the first step of the four-step staged management algorithm for DED.

The current study identified current clinical practice patterns in primary eye care, as related to oral omega-3 fatty acids, and highlighted knowledge gaps and perceived barriers to clinical implementation. There were some limitations to the present study. While the cohort represented a broad range of optometric practice locations and modalities, there was the potential for self-selection bias, and this was reflected in the proportion of participants declaring a clinical interest in DED or ocular surface disease. Also noted was a relative over-representation of younger optometrists, and optometrists working in independent (private) practice. These limitations may affect the generalizability of our findings, but are not uncommon considerations in survey-based research.

\section{Conclusions}

Our results suggest that most Australian and New Zealand optometrists routinely provide clinical recommendations about diet and nutritional strategies, as relevant to eye health. While many optometrists indicated recommending diet-based strategies for managing AMD, the potential benefits of whole-food omega-3 sources relative to the limited benefits of omega-3 supplements were not consistently appreciated. Most respondents recommended omega-3 fatty acids for managing DED, despite conflicting data from recent randomized trials. Respondents were more likely to recommend omega-3 fatty acids to patients with moderate or severe (rather than mild) DED, and to use omega-3 supplementation to treat predominantly evaporative DED. Further research is needed to address uncertainties in the evidence relating to the optimal prescribing regimen (i.e., omega- 3 dose and formulation composition) for treating DED. This information will be of value for informing future 
education programs about eye health and nutrition, particularly at events such as clinical education conferences that were reported to form the main source of information used by optometrists to guide clinical decision-making.

Author Contributions: Conceptualization, A.C.Z., J.P.C., and L.E.D.; methodology, A.C.Z., J.P.C., and L.E.D.; formal analysis, A.C.Z. and S.S.; investigation and data collection, A.C.Z., J.P.C., and L.E.D.; writing-original draft preparation, A.C.Z.; writing-review and editing, J.P.C., S.S., and L.E.D. All authors have read and agreed to the published version of the manuscript.

Funding: This research received no external funding. A.C.Z. was supported by an Australian Government Research Training Program Scholarship for her PhD studies. S.S. was supported by a Melbourne International Research Training Scholarship for his PhD studies.

Acknowledgments: We thank the following organizations for their assistance in distributing this survey: Optometry Australia, Cornea and Contact Lens Society of Australia, Early Career Optometrists Victoria/Tasmania, Young Optometrists New South Wales/Australian Capital Territory, New Zealand Association of Optometrists, and Cornea and Contact Lens Society, New Zealand.

Conflicts of Interest: J.P.C. acknowledges University laboratory funding from Alcon, Azura Ophthalmics, E-Swin, Manuka Health NZ and Théa Laboratories for research in the area of dry eye and ocular surface disease, not specifically related to essential fatty acids, as well as consultancy, speaker, or travel funding from Azura Ophthalmics, E-Swin, Novartis, Shire and Théa Laboratories. L.E.D.'s research laboratory, University of Melbourne, has previously received funding from CooperVision Pty Ltd for a clinical trial investigating omega-3 fatty acid supplementation for treating contact lens discomfort, unrelated to the present study. In the past 3 years, L.E.D's research laboratory has also received funding from Azura Ophthalmics, CooperVision Pty Ltd and Allergan Pty Ltd., unrelated to the present study. L.E.D. has also received consultancy income from her research laboratory from Seqirus Pty Ltd and Medmont Pty Ltd, unrelated to this study. All other authors declare no relevant conflicts of interest.

\section{Appendix A}

Table A1. Knowledge questions surveyed and, in bold, answers considered as 'correct' for deriving an 'omega-3 knowledge score'.

Questions (Answer Considered 'Correct' in Bold)

There are two forms of omega-3 fatty acids, derived either from plant-based sources (e.g., chia seeds, walnuts, flaxseed) or marine-based foods (e.g., fish and seafood).

3.1 Which of the following do you consider to best describe the difference between plant-based and marine-based omega- 3 fatty acids, if they are consumed at the same dose?

(a) Plant-based (short-chain) omega-3 fatty acids have MORE biological effect than marine-based (long-chain) omega-3 fatty acids

(b) Plant-based (short-chain) omega-3 fatty acids have LESS biological effect than marine-based (long-chain) omega-3 fatty acids

(c) Plant-based (short-chain) omega-3 fatty acids have the SAME biological effect as marine-based (long-chain) omega-3 fatty acids

(d) Don't know

Omega-6s are the other main form of essential fatty acids. For the next two questions, consider which option best describes the biological roles of omega- 3 and omega- 6 fatty acids.

3.2 Omega-3 fatty acids are:
(a) Always anti-inflammatory
(b) Mostly anti-inflammatory
(c) Equally anti-inflammatory and pro-inflammatory
(d) Mostly pro-inflammatory
(e) Always pro-inflammatory 
Table A1. Cont.

\begin{tabular}{l} 
Questions (Answer Considered 'Correct' in Bold) \\
\hline 3.3 Omega-6 fatty acids are: \\
(a) Always anti-inflammatory \\
(b) Mostly anti-inflammatory \\
(c) Equally anti-inflammatory and pro-inflammatory \\
(d) Mostly pro-inflammatory \\
(e) Always pro-inflammatory \\
\hline 3.4 Based upon your current knowledge, what do you consider to be an ideal ratio of omega-6 \\
to omega-3 in the human diet? \\
(a) $10: 1$ \\
(b) $4: 1$ \\
(c) $1: 1$ \\
(d) $1: 4$ \\
(e) $1: 10$ \\
3.5 Based on your understanding, which of the following options would you consider to be \\
closest to the ideal approximate adult dietary target of long-chain (marine-based) omega-3 \\
fatty acids (from food and/or supplementation)? \\
(a) $100 \mathrm{mg}$ /day \\
(b) $250 \mathrm{mg} /$ day \\
(c) $500 \mathrm{mg} /$ day \\
(d) $1000 \mathrm{mg} /$ day \\
(e) $1500 \mathrm{mg} /$ day
\end{tabular}

\section{References}

1. Lawrenson, J.G.; Downie, L.E. Nutrition and Eye Health. Nutrients 2019, 11, 2123. [CrossRef] [PubMed]

2. Calder, P.C.; Grimble, R.F. Polyunsaturated fatty acids, inflammation and immunity. Eur. J. Clin. Nutr. 2002, 56 (Suppl. 3), S14-S19. [CrossRef] [PubMed]

3. Barcelo-Coblijn, G.; Collison, L.W.; Jolly, C.A.; Murphy, E.J. Dietary alpha-linolenic acid increases brain but not heart and liver docosahexaenoic acid levels. Lipids 2005, 40, 787-798. [CrossRef] [PubMed]

4. Emken, E.A.; Adlof, R.O; Gulley, R.M. Dietary linoleic acid influences desaturation and acylation of deuterium-labeled linoleic and linolenic acids in young adult males. Biochim. Biophys. Acta 1994, 1213, 277-288. [CrossRef]

5. Gerster, H. Can adults adequately convert alpha-linolenic acid (18:3n-3) to eicosapentaenoic acid (20:5n-3) and docosahexaenoic acid (22:6n-3)? Int. J. Vitam. Nutr. Res. 1998, 68, 159-173.

6. Nettleton, J.A. Omega-3 fatty acids: Comparison of plant and seafood sources in human nutrition. J. Am. Diet Assoc. 1991, 91, 331-337.

7. Janssen, C.I.; Kiliaan, A.J. Long-chain polyunsaturated fatty acids (LCPUFA) from genesis to senescence: The influence of LCPUFA on neural development, aging, and neurodegeneration. Prog. Lipid Res. 2014, 53, 1-17. [CrossRef]

8. Simopoulos, A.P. The importance of the ratio of omega-6/omega-3 essential fatty acids. Biomed. Pharmacother. 2002, 56, 365-379. [CrossRef]

9. Meyer, B.J. Australians are not Meeting the Recommended Intakes for Omega-3 Long Chain Polyunsaturated Fatty Acids: Results of an Analysis from the 2011-2012 National Nutrition and Physical Activity Survey. Nutrients 2016, 8, 111. [CrossRef]

10. Rand, A.L.; Asbell, P.A. Nutritional supplements for dry eye syndrome. Curr. Opin. Ophthalmol. 2011, 22, 279-282. [CrossRef]

11. SanGiovanni, J.P.; Chew, E.Y. The role of omega-3 long-chain polyunsaturated fatty acids in health and disease of the retina. Prog. Retin. Eye Res. 2005, 24, 87-138. [CrossRef] [PubMed]

12. Stapleton, F.; Alves, M.; Bunya, V.Y.; Jalbert, I.; Lekhanont, K.; Malet, F.; Na, K.S.; Schaumberg, D.; Uchino, M.; Vehof, J.; et al. TFOS DEWS II Epidemiology Report. Ocul. Surf. 2017, 15, 334-365. [CrossRef] [PubMed] 
13. McDonald, M.; Patel, D.A.; Keith, M.S.; Snedecor, S.J. Economic and Humanistic Burden of Dry Eye Disease in Europe, North America, and Asia: A Systematic Literature Review. Ocul. Surf. 2016, 14, 144-167. [CrossRef] [PubMed]

14. Patel, V.D.; Watanabe, J.H.; Strauss, J.A.; Dubey, A.T. Work productivity loss in patients with dry eye disease: An online survey. Curr. Med. Res. Opin. 2011, 27, 1041-1048. [CrossRef]

15. Craig, J.P.; Nichols, K.K.; Akpek, E.K.; Caffery, B.; Dua, H.S.; Joo, C.K.; Liu, Z.; Nelson, J.D.; Nichols, J.J.; Tsubota, K.; et al. TFOS DEWS II Definition and Classification Report. Ocul. Surf. 2017, 15, 276-283. [CrossRef]

16. Bron, A.J.; de Paiva, C.S.; Chauhan, S.K.; Bonini, S.; Gabison, E.E.; Jain, S.; Knop, E.; Markoulli, M.; Ogawa, Y.; Perez, V.; et al. TFOS DEWS II pathophysiology report. Ocul. Surf. 2017, 15, 438-510. [CrossRef]

17. Sullivan, B.D.; Cermak, J.M.; Sullivan, R.M.; Papas, A.S.; Evans, J.E.; Dana, M.R.; Sullivan, D.A. Correlations between nutrient intake and the polar lipid profiles of meibomian gland secretions in women with Sjogren's syndrome. Adv. Exp. Med. Biol. 2002, 506, 441-447. [CrossRef]

18. Walter, S.D.; Gronert, K.; McClellan, A.L.; Levitt, R.C.; Sarantopoulos, K.D.; Galor, A. w-3 Tear Film Lipids Correlate With Clinical Measures of Dry Eye. Investig. Ophthalmol. Vis. Sci. 2016, 57, 2472-2478. [CrossRef]

19. Miljanovic, B.; Trivedi, K.A.; Dana, M.R.; Gilbard, J.P.; Buring, J.E.; Schaumberg, D.A. Relation between dietary n-3 and n-6 fatty acids and clinically diagnosed dry eye syndrome in women. Am. J. Clin. Nutr. 2005, 82, 887-893. [CrossRef]

20. Asbell, P.A.; Maguire, M.G.; Pistilli, M.; Ying, G.S.; Szczotka-Flynn, L.B.; Hardten, D.R.; Lin, M.C.; Shtein, R.M. n-3 Fatty Acid Supplementation for the Treatment of Dry Eye Disease. N. Engl. J. Med. 2018, 378, 1681-1690. [CrossRef]

21. Deinema, L.A.; Vingrys, A.J.; Wong, C.Y.; Jackson, D.C.; Chinnery, H.R.; Downie, L.E. A Randomized, Double-Masked, Placebo-Controlled Clinical Trial of Two Forms of Omega-3 Supplements for Treating Dry Eye Disease. Ophthalmology 2017, 124, 43-52. [CrossRef]

22. Epitropoulos, A.T.; Donnenfeld, E.D.; Shah, Z.A.; Holland, E.J.; Gross, M.; Faulkner, W.J.; Matossian, C.; Lane, S.S.; Toyos, M.; Bucci, F.A.J.; et al. Effect of Oral Re-esterified Omega-3 Nutritional Supplementation on Dry Eyes. Cornea 2016, 35, 1185-1191. [CrossRef] [PubMed]

23. Kangari, H.; Eftekhari, M.H.; Sardari, S.; Hashemi, H.; Salamzadeh, J.; Ghassemi-Broumand, M.; Khabazkhoob, M. Short-term Consumption of Oral Omega-3 and Dry Eye Syndrome. Ophthalmology 2013, 120, 2191-2196. [CrossRef] [PubMed]

24. Wojtowicz, J.C.; Butovich, I.; Uchiyama, E.; Aronowicz, J.; Agee, S.; McCulley, J.P. Pilot, prospective, randomized, double-masked, placebo-controlled clinical trial of an omega-3 supplement for dry eye. Cornea 2011, 30, 308-314. [CrossRef] [PubMed]

25. Downie, L.E.; Ng, S.M.; Lindsley, K.B.; Akpek, E.K. Omega-3 and omega-6 polyunsaturated fatty acids for dry eye disease. Cochrane Database Syst. Rev. 2019, CD011016. [CrossRef] [PubMed]

26. Van Leeuwen, E.M.; Emri, E.; Merle, B.M.J.; Colijn, J.M.; Kersten, E.; Cougnard-Gregoire, A.; Dammeier, S.; Meester-Smoor, M.; Pool, F.M.; de Jong, E.K.; et al. A new perspective on lipid research in age-related macular degeneration. Prog. Retin. Eye Res. 2018, 67, 56-86. [CrossRef]

27. Reme, C.E.; Malnoe, A.; Jung, H.H.; Wei, Q.; Munz, K. Effect of dietary fish oil on acute light-induced photoreceptor damage in the rat retina. Investig. Ophthalmol. Vis. Sci. 1994, 35, 78-90.

28. Tuo, J.; Ross, R.J.; Herzlich, A.A.; Shen, D.; Ding, X.; Zhou, M.; Coon, S.L.; Hussein, N.; Salem, N., Jr.; Chan, C.-C. A high omega-3 fatty acid diet reduces retinal lesions in a murine model of macular degeneration. Am. J. Pathol. 2009, 175, 799-807. [CrossRef]

29. Simón, M.V.; Agnolazza, D.L.; German, O.L.; Garelli, A.; Politi, L.E.; Agbaga, M.-P.; Anderson, R.E.; Rotstein, N.P. Synthesis of docosahexaenoic acid from eicosapentaenoic acid in retina neurons protects photoreceptors from oxidative stress. J. Neurochem. 2016, 136, 931-946. [CrossRef]

30. Tan, J.S.; Wang, J.J.; Flood, V.; Mitchell, P. Dietary fatty acids and the 10-year incidence of age-related macular degeneration: The Blue Mountains Eye Study. Arch. Ophthalmol. 2009, 127, 656-665. [CrossRef]

31. Wu, J.; Cho, E.; Giovannucci, E.L.; Rosner, B.A.; Sastry, S.M.; Willett, W.C.; Schaumberg, D.A. Dietary Intakes of Eicosapentaenoic Acid and Docosahexaenoic Acid and Risk of Age-Related Macular Degeneration. Ophthalmology 2017, 124, 634-643. [CrossRef] [PubMed]

32. Lawrenson, J.G.; Evans, J.R. Omega 3 fatty acids for preventing or slowing the progression of age-related macular degeneration. Cochrane Database Syst. Rev. 2015, 4, CD010015. [CrossRef] [PubMed] 
33. Merle, B.M.J.; Colijn, J.M.; Cougnard-Gregoire, A.; de Koning-Backus, A.P.M.; Delyfer, M.N.; Kiefte-de Jong, J.C.; Meester-Smoor, M.; Feart, C.; Verzijden, T.; Samieri, C.; et al. Mediterranean Diet and Incidence of Advanced Age-Related Macular Degeneration: The EYE-RISK Consortium. Ophthalmology 2018, 126, 381-390. [CrossRef] [PubMed]

34. Lawrenson, J.G.; Evans, J.R. Advice about diet and smoking for people with or at risk of age-related macular degeneration: A cross-sectional survey of eye care professionals in the UK. BMC Public Health 2013, 13, 564. [CrossRef]

35. Downie, L.E.; Keller, P.R. The self-reported clinical practice behaviors of Australian optometrists as related to smoking, diet and nutritional supplementation. PLoS ONE 2015, 10, e0124533. [CrossRef]

36. Kiely, P.M.; Slater, J. Optometry Australia Entry-level Competency Standards for Optometry 2014. Clin. Exp. Optom. 2015, 98, 65-89. [CrossRef]

37. Downie, L.E.; Douglass, A.; Guest, D.; Keller, P.R. What do patients think about the role of optometrists in providing advice about smoking and nutrition? Ophthalmic Physiol. Opt. 2017, 37, 202-211. [CrossRef]

38. Age-Related Eye Disease Study Research Group. A randomized, placebo-controlled, clinical trial of high-dose supplementation with vitamins $\mathrm{C}$ and $\mathrm{E}$, beta carotene, and zinc for age-related macular degeneration and vision loss: AREDS report no. 8. Arch. Ophthalmol. 2001, 119, 1417-1436. [CrossRef]

39. Australian Government Department of Health. Health Workforce Data: Optometrists 2017 Factsheet. Available online: https://hwd.health.gov.au (accessed on 1 February 2020).

40. Naroo, S.A.; Grit, F. Optometry and optics in Europe. Contact Lens Anterior Eye 2009, 32, 101-102. [CrossRef]

41. George, P.P.; Yun, O.C.S.; Siow, K.; Saxena, N.; Heng, B.H.; Car, J.; Lockwood, C. Is there scope for expanding the optometrist's scope of practice in Singapore?-A survey of optometrists, opticians in Singapore. Contact Lens Anterior Eye 2019, 42, 258-264. [CrossRef]

42. Stein, J.D.; Kapoor, K.G.; Tootoo, J.L.; Li, R.; Wagner, A.; Andrews, C.; Miranda, M.L. Access to Ophthalmologists in States Where Optometrists Have Expanded Scope of Practice. JAMA Ophthalmol. 2018, 136, 39-45. [CrossRef] [PubMed]

43. Black, J.M.; Jacobs, R.J.; Phillips, J.R.; Acosta, M.L. The changing scope of Optometry in New Zealand: Historical perspectives, current practice and research advances. J. R. Soc. N. Z. 2019, 49, 188-204. [CrossRef]

44. Harper, R.; Creer, R.; Jackson, J.; Ehrlich, D.; Tompkin, A.; Bowen, M.; Tromans, C. Scope of practice of optometrists working in the UK Hospital Eye Service: A national survey. Ophthalmic Physiol. Opt. 2016, 36, 197-206. [CrossRef] [PubMed]

45. Optometry Board of Australia. Optometry Board of Australia Registrant Data: Reporting Period: 01 October 2019 to 31 December 2019. Available online: https://optometryboard.com.au (accessed on 1 February 2020).

46. SanGiovanni, J.P.; Chew, E.Y.; Agron, E.; Clemons, T.E.; Ferris, F.L., 3rd; Gensler, G.; Lindblad, A.S.; Milton, R.C.; Seddon, J.M.; Klein, R.; et al. The relationship of dietary omega-3 long-chain polyunsaturated fatty acid intake with incident age-related macular degeneration: AREDS report no. 23. Arch. Ophthalmol. 2008, 126, 1274-1279. [CrossRef] [PubMed]

47. De Koning-Backus, A.P.M.; Buitendijk, G.H.S.; Kiefte-de Jong, J.C.; Colijn, J.M.; Hofman, A.; Vingerling, J.R.; Haverkort, E.B.; Franco, O.H.; Klaver, C.C.W. Intake of Vegetables, Fruit, and Fish is Beneficial for Age-Related Macular Degeneration. Am. J. Ophthalmol. 2019, 198, 70-79. [CrossRef]

48. Chong, E.W.; Kreis, A.J.; Wong, T.Y.; Simpson, J.A.; Guymer, R.H. Dietary omega-3 fatty acid and fish intake in the primary prevention of age-related macular degeneration: A systematic review and meta-analysis. Arch. Ophthalmol. 2008, 126, 826-833. [CrossRef]

49. Zhu, W.; Wu, Y.; Meng, Y.F.; Xing, Q.; Tao, J.J.; Lu, J. Fish Consumption and Age-Related Macular Degeneration Incidence: A Meta-Analysis and Systematic Review of Prospective Cohort Studies. Nutrients 2016, 8, 743. [CrossRef]

50. Chew EY, C.T.; SanGiovanni, J.P.; Danis, R.; Ferris, F.L., 3rd; Elman, M.; Antoszyk, A.; Ruby, A.; Orth, D.; Bressler, S.; Fish, G.; et al. Age-Related Eye Disease Study 2 Research Group. Lutein + zeaxanthin and omega-3 fatty acids for age-related macular degeneration: The Age-Related Eye Disease Study 2 (AREDS2) randomized clinical trial. JAMA 2013, 309, 2005-2015. [CrossRef]

51. Seddon, J.M.; Ajani, U.A.; Sperduto, R.D.; Hiller, R.; Blair, N.; Burton, T.C.; Farber, M.D.; Gragoudas, E.S.; Haller, J.; Miller, D.T.; et al. Dietary carotenoids, vitamins A, C, and E, and advanced age-related macular degeneration. Eye Disease Case-Control Study Group. JAMA 1994, 272, 1413-1420. [CrossRef] 
52. Offman, E.; Marenco, T.; Ferber, S.; Johnson, J.; Kling, D.; Curcio, D.; Davidson, M. Steady-state bioavailability of prescription omega- 3 on a low-fat diet is significantly improved with a free fatty acid formulation compared with an ethyl ester formulation: The ECLIPSE II study. Vasc. Health Risk Manag. 2013, 9, 563-573. [CrossRef]

53. Dyerberg, J.; Madsen, P.; Moller, J.M.; Aardestrup, I.; Schmidt, E.B. Bioavailability of marine n-3 fatty acid formulations. Prostaglandins Leukot. Essent. Fat. Acids 2010, 83, 137-141. [CrossRef] [PubMed]

54. Downie, L.E.; Keller, P.R. Nutrition and age-related macular degeneration: Research evidence in practice. Optom. Vis. Sci. 2014, 91, 821-831. [CrossRef] [PubMed]

55. Downie, L.E.; Rumney, N.; Gad, A.; Keller, P.R.; Purslow, C.; Vingrys, A.J. Comparing self-reported optometric dry eye clinical practices in Australia and the United Kingdom: Is there scope for practice improvement? Ophthalmic Physiol. Opt. 2016, 36, 140-151. [CrossRef] [PubMed]

56. Xue, A.L.; Downie, L.E.; Ormonde, S.E.; Craig, J.P. A comparison of the self-reported dry eye practices of New Zealand optometrists and ophthalmologists. Ophthalmic Physiol. Opt. 2017, 37, 191-201. [CrossRef] [PubMed]

57. Liu, Y.; Kam, W.R.; Sullivan, D.A. Influence of Omega 3 and 6 Fatty Acids on Human Meibomian Gland Epithelial Cells. Cornea 2016, 35, 1122-1126. [CrossRef]

58. Macsai, M.S. The role of omega-3 dietary supplementation in blepharitis and meibomian gland dysfunction (an AOS thesis). Trans. Am. Ophthalmol. Soc. 2008, 106, 336-356. [PubMed]

59. Jones, L.; Downie, L.E.; Korb, D.; Benitez-Del-Castillo, J.M.; Dana, R.; Deng, S.X.; Dong, P.N.; Geerling, G.; Hida, R.Y.; Liu, Y.; et al. TFOS DEWS II Management and Therapy Report. Ocul. Surf. 2017, 15, 575-628. [CrossRef]

60. Skulas-Ray, A.C.; Wilson, P.W.F.; Harris, W.S.; Brinton, E.A.; Kris-Etherton, P.M.; Richter, C.K.; Jacobson, T.A.; Engler, M.B.; Miller, M.; Robinson, J.G.; et al. Omega-3 Fatty Acids for the Management of Hypertriglyceridemia: A Science Advisory From the American Heart Association. Circulation 2019, 140, e673-e691. [CrossRef]

61. Guu, T.W.; Mischoulon, D.; Sarris, J.; Hibbeln, J.; McNamara, R.K.; Hamazaki, K.; Freeman, M.P.; Maes, M.; Matsuoka, Y.J.; Belmaker, R.H.; et al. International Society for Nutritional Psychiatry Research Practice Guidelines for Omega-3 Fatty Acids in the Treatment of Major Depressive Disorder. Psychother. Psychosom. 2019, 88, 263-273. [CrossRef]

62. Downie, L.E.; Gad, A.; Wong, C.Y.; Gray, J.H.V.; Zeng, W.; Jackson, D.C.; Vingrys, A.J. Modulating Contact Lens Discomfort With Anti-Inflammatory Approaches: A Randomized Controlled Trial. Investig. Ophthalmol. Vis. Sci. 2018, 59, 3755-3766. [CrossRef]

63. Downie, L.E.; Hom, M.M.; Berdy, G.J.; El-Harazi, S.; Verachtert, A.; Tan, J.; Liu, H.; Carlisle-Wilcox, C.; Simmons, P.; Vehige, J. An artificial tear containing flaxseed oil for treating dry eye disease: A randomized controlled trial. Ocul. Surf. 2020, 18, 148-157. [CrossRef] [PubMed]

64. Aragona, P.; Bucolo, C.; Spinella, R.; Giuffrida, S.; Ferreri, G. Systemic Omega-6 Essential Fatty Acid Treatment and PGE1 Tear Content in Sjogren's Syndrome Patients. Investig. Ophthalmol. Vis. Sci. 2005, 46, 4474-4479. [CrossRef] [PubMed]

65. Ziemanski, J.F.; Wolters, L.R.; Jones-Jordan, L.; Nichols, J.J.; Nichols, K.K. Relation Between Dietary Essential Fatty Acid Intake and Dry Eye Disease and Meibomian Gland Dysfunction in Postmenopausal Women. Am. J. Ophthalmol. 2018, 189, 29-40. [CrossRef]

66. Barabino, S.; Rolando, M.; Camicione, P.; Ravera, G.; Zanardi, S.; Giuffrida, S.; Calabria, G. Systemic linoleic and gamma-linolenic acid therapy in dry eye syndrome with an inflammatory component. Cornea 2003, 22, 97-101. [CrossRef] [PubMed]

67. Brignole-Baudouin, F.; Baudouin, C.; Aragona, P.; Rolando, M.; Labetoulle, M.; Pisella, P.J.; Barabino, S.; Siou-Mermet, R.; Creuzot-Garcher, C. A multicentre, double-masked, randomized, controlled trial assessing the effect of oral supplementation of omega-3 and omega- 6 fatty acids on a conjunctival inflammatory marker in dry eye patients. Acta Ophthal. 2011, 89, e591-e597. [CrossRef] [PubMed]

68. Rice, H.B.; Bernasconi, A.; Maki, K.C.; Harris, W.S.; von Schacky, C.; Calder, P.C. Conducting omega-3 clinical trials with cardiovascular outcomes: Proceedings of a workshop held at ISSFAL 2014. Prostaglandins Leukot. Essent. Fat. Acids 2016, 107, 30-42. [CrossRef]

69. Zhang, A.C.; Downie, L.E. Preliminary Validation of a Food Frequency Questionnaire to Assess Long-Chain Omega-3 Fatty Acid Intake in Eye Care Practice. Nutrients 2019, 11, 817. [CrossRef] 
70. National Health and Medical Research Council. Nutrient Reference Values for Australia and New Zealand including Recommended Dietary Intakes; Australian Government Department of Health and Ageing: Canberra, Australia, 2006.

71. Burdge, G.C. Metabolism of $\alpha$-linolenic acid in humans. Prostaglandins Leukot. Essent. Fat. Acids 2006, 75, 161-168. [CrossRef]

72. Calder, P.C. Mechanisms of action of (n-3) fatty acids. J. Nutr. 2012, 142, 592s-599s. [CrossRef]

73. Bays, H.E. Safety considerations with omega-3 fatty acid therapy. Am. J. Cardiol. 2007, 99, 35c-43c. [CrossRef]

74. Villani, A.M.; Crotty, M.; Cleland, L.G.; James, M.J.; Fraser, R.J.; Cobiac, L.; Miller, M.D. Fish oil administration in older adults: Is there potential for adverse events? A systematic review of the literature. BMC Geriatr. 2013, 13, 41. [CrossRef] [PubMed]

75. Chang, C.H.; Tseng, P.T.; Chen, N.Y.; Lin, P.C.; Lin, P.Y.; Chang, J.P.; Kuo, F.Y.; Lin, J.; Wu, M.C.; Su, K.P. Safety and tolerability of prescription omega-3 fatty acids: A systematic review and meta-analysis of randomized controlled trials. Prostaglandins Leukot. Essent. Fat. Acids 2018, 129, 1-12. [CrossRef] [PubMed]

76. Suttle, C.M.; Challinor, K.L.; Thompson, R.E.; Pesudovs, K.; Togher, L.; Chiavaroli, N.; Lee, A.; Junghans, B.; Stapleton, F.; Watt, K.; et al. Attitudes and barriers to evidence-based practice in optometry educators. Optom. Vis. Sci. 2015, 92, 514-523. [CrossRef] [PubMed]

77. Optometry Australia: Clinical Practice Guide for the Diagnosis, Treatment and Management of Age-Related Macular Degeneration. Optometry Austraia. 2019. Available online: https://www.optometry.org.au (accessed on 1 February 2020).

78. Craig, J.P.; Nelson, J.D.; Azar, D.T.; Belmonte, C.; Bron, A.J.; Chauhan, S.K.; de Paiva, C.S.; Gomes, J.A.P.; Hammitt, K.M.; Jones, L.; et al. TFOS DEWS II Report Executive Summary. Ocul. Surf. 2017, 15, 802-812. [CrossRef] [PubMed]

(C) 2020 by the authors. Licensee MDPI, Basel, Switzerland. This article is an open access article distributed under the terms and conditions of the Creative Commons Attribution (CC BY) license (http://creativecommons.org/licenses/by/4.0/). 